\title{
Determinação de taninos em plantas com potencial forrageiro para ruminantes
}

\author{
Eduardo Fernando Nozella
}

Dissertação apresentada ao Centro de Energia Nuclear na Agricultura, da Universidade de São Paulo, para a obtenção do título de Mestre em Ciências. Área de Concentração: Energia Nuclear na Agricultura

\author{
Piracicaba \\ Estado de São Paulo - Brasil \\ Dezembro - 2001
}




\section{Determinação de taninos em plantas com potencial forrageiro para ruminantes}

\section{EduARdo Fernando Nozella}

Zootecnista

Orientadora: Profa. Dra. DORINHA MIRIAM SILBER SCHMIDT VITTI

Dissertação apresentada ao Centro de Energia Nuclear na Agricultura, da Universidade de São Paulo, para a obtenção do título de Mestre em Ciências. Área de Concentração: Energia Nuclear na Agricultura

Piracicaba

Estado de São Paulo - Brasil

Dezembro - 2001 
Dados Internacionais de Catalogação na Publicação (CIP) Seção Técnica de Biblioteca - CENA/USP

Nozella, Eduardo Fernando

Determinação de taninos em plantas com potencial forrageiro para ruminantes / Eduardo Fernando Nozella. - - Piracicaba, 2001.

58p. : il.

Dissertação (mestrado) - - Centro de Energia Nuclear na Agricultura, 2001.

1. Análise bromatológica 2. Análise de alimentos para animal 3. Degradabilidade 4. Leguminosas forrageiras 5. PVPP I. Título

CDU 591.133.1 
Dedico:

aos meus pais, pelo esforço para a minha formação, a minha avó Ana e a minha noiva Juliana pela dedicação e paciência, o presente trabalho. 
Agradeço a todos que de alguma forma contribuíram para a realização desse trabalho. Em especial expresso minha gratidão às seguintes pessoas:

à Profa. Dra. Dorinha Miriam Silber Schmidt Vitti pelo incentivo e orientação do trabalho;

ao Centro de Energia Nuclear na Agricultura, por conceder-me a oportunidade da realização dos meus estudos;

à FAPESP, por financiar os estudos através do apoio financeiro concedido;

à equipe de pesquisadores do Laboratório de Nutrição Animal do CENA pelo incentivo;

aos colegas Sergio Lucio S. Cabral Filho, Ives C. da Silva Bueno, Sarita S. Gobbo, Mariana de Carvalho Machado pelo auxílio na condução do experimento, estímulo e amizade;

aos funcionários Lécio A. Castilho e Maria Regina S. R. Peçanha pela colaboração no trabalho com os animais e auxílio nos procedimentos analíticos realizados;

aos estagiários José Antonio C. de Castro, Daniela de Paula Silveira e Ana Paola Negri pela ajuda oferecida sempre que necessário. 


\section{SUMÁRIO}

Página

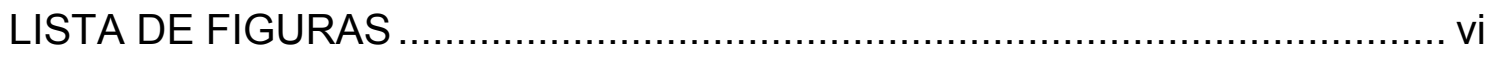

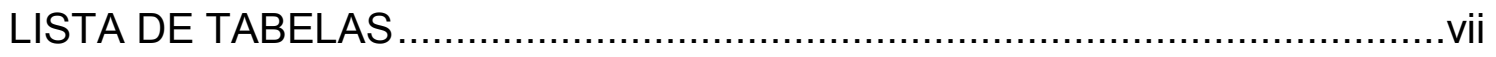

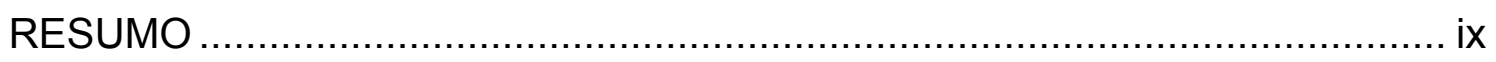

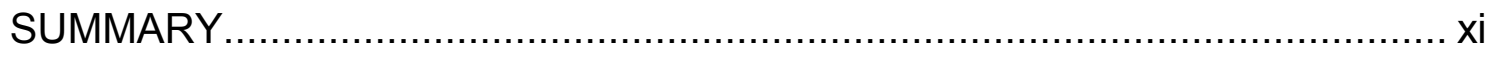

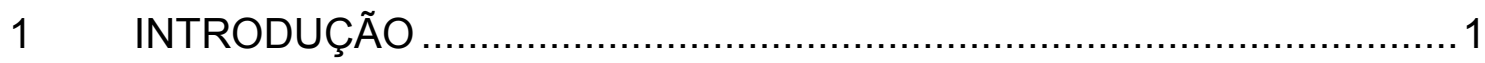

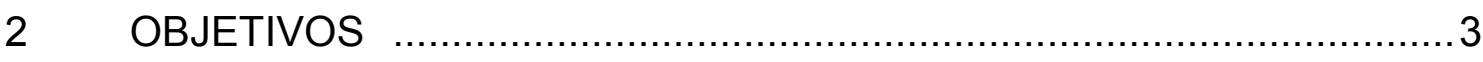

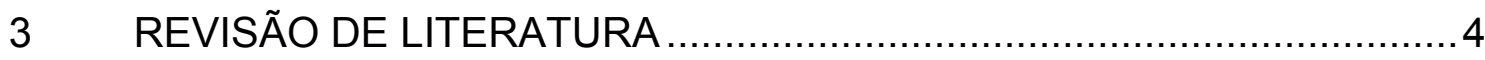

3.1 Taninos: bioquímica e propriedades nutricionais ................................. 4

3.1.1 Definição e ocorrência.................................................................... 4

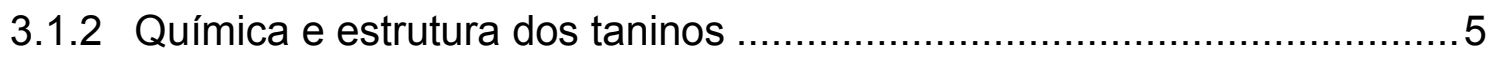

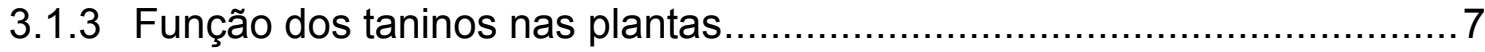

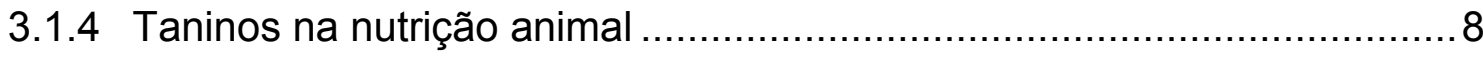

3.1.4.1 Efeitos benéficos dos taninos .................................................. 10

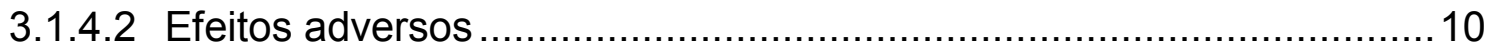

3.1.4.3 Toxidade dos taninos aos microrganismos do rúmen e

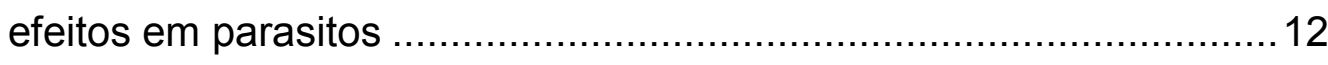

3.1.5 Métodos para reduzir os efeitos antinutricionais dos taninos ................ 13

3.1.6 Métodos de quantificação dos taninos .............................................. 14

3.2 Incorporação in vitro do ${ }^{32} \mathrm{P}$ e síntese microbiana ................................... 16

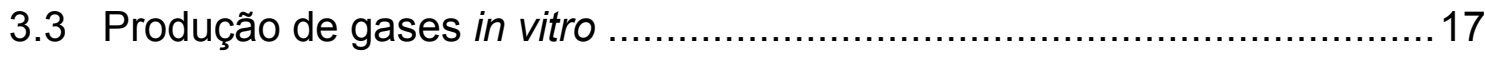

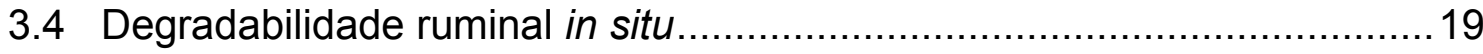




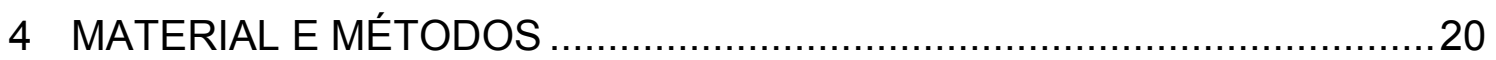

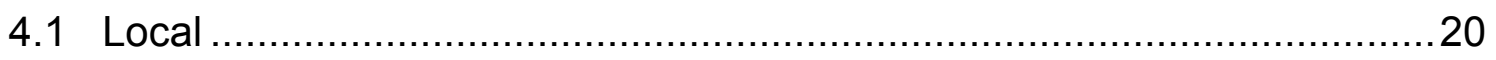

4.2 Substratos utilizados e preparo das amostras para análises ...................20

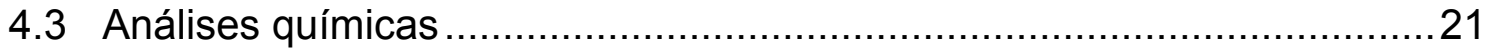

4.3.1 Determinação de fenóis totais, taninos e taninos condensados.............22

4.3.1.1 Extração das frações solúveis ....................................................... 22

4.3.1.2 Curva padrão para compostos fenólicos e taninos ............................ 22

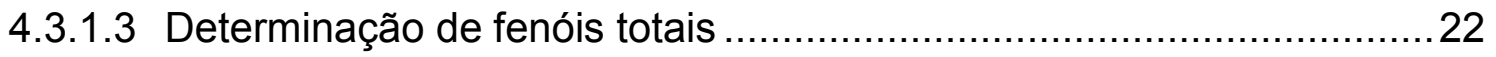

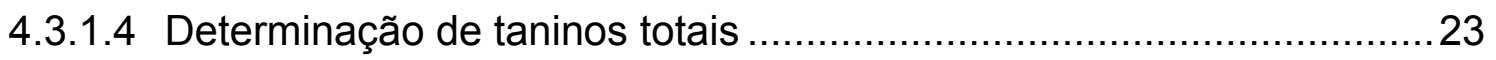

4.3.1.5 Determinação de taninos condensados ...........................................24

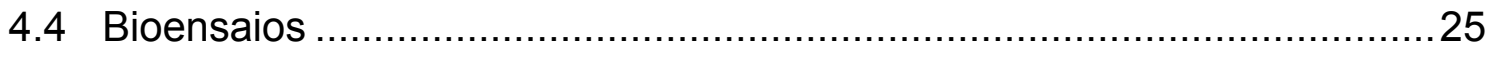

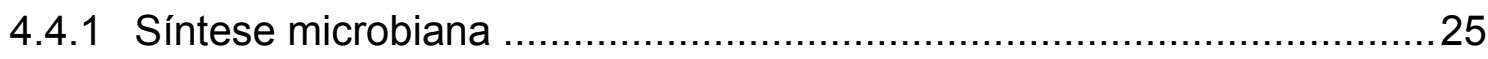

4.4.1.1 Determinação de fósforo inorgânico no sobrenadante .......................26

4.4.1.2 Cálculos da incorporação microbiana.............................................2

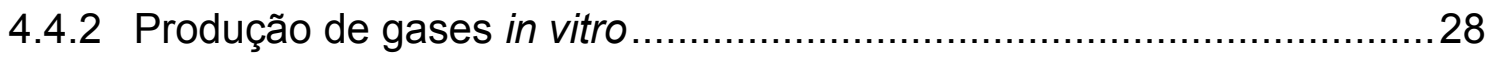

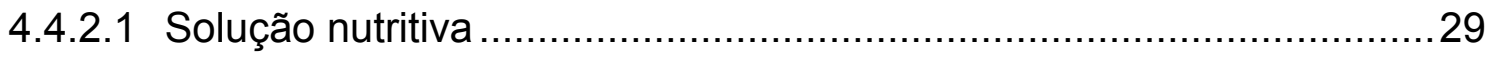

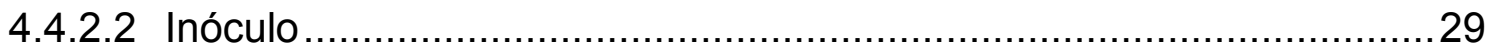

4.4.2.3 Incubação e medidas de pressão ....................................................... 30

4.4.2.4 Digestibilidade in vitro da matéria seca ...........................................30

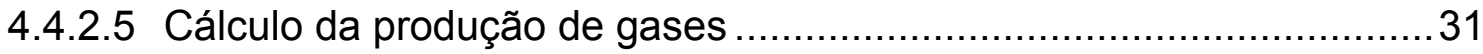

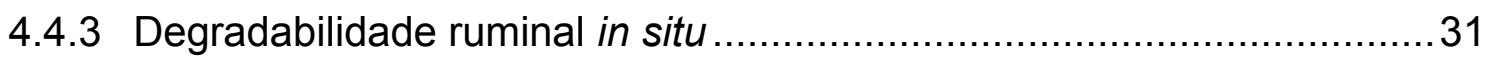

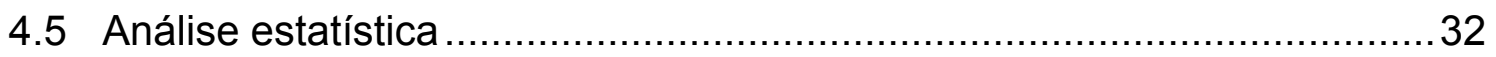

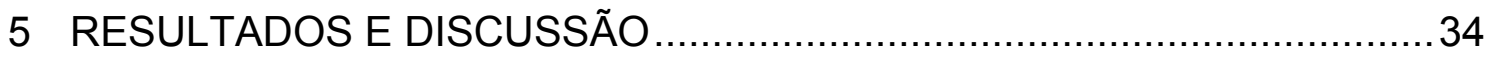

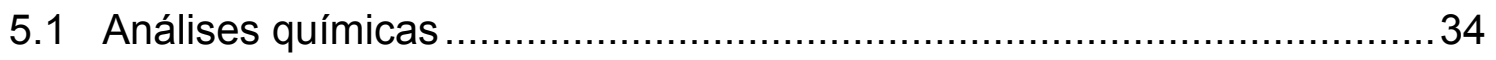

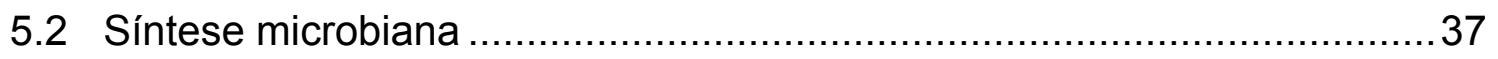

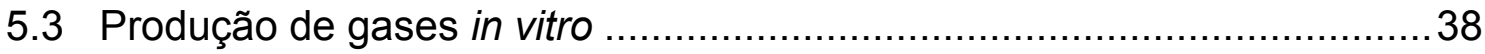

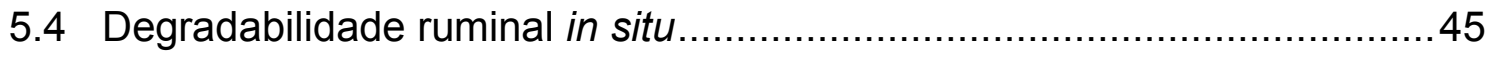

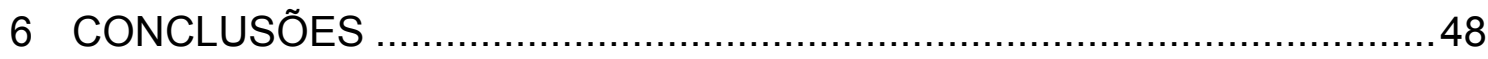

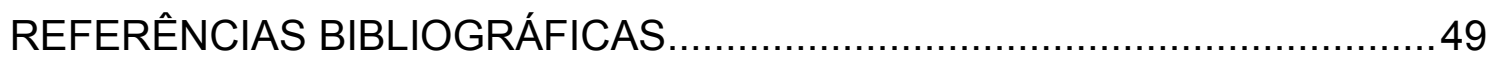




\section{LISTA DE FIGURAS}

Página

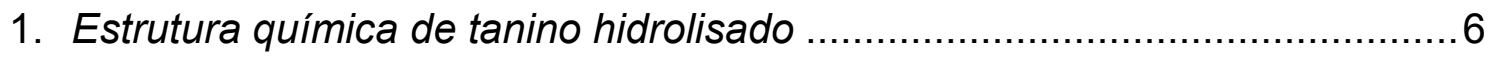

2. Estrutura química de tanino condensado .............................................

3. Curvas de produção acumulada de gases (em $\mathrm{ml} \cdot \mathrm{g}^{-1} \mathrm{MS}$ ) evidenciando a cinética do processo fermentativo sem e com

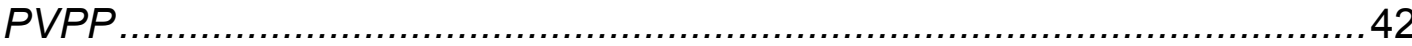




\section{LISTA DE TABELAS}

Página

1. Nomes vulgares, científicos, classificação (famílias) das plantas utilizadas e locais de coletas 21

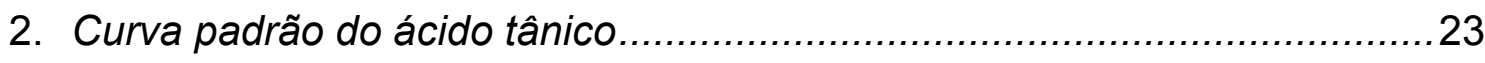

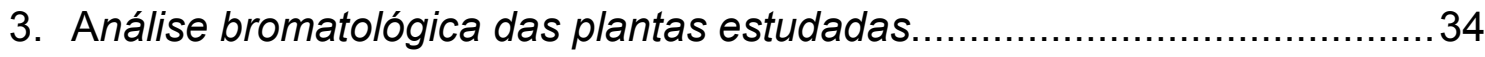

4. Resultados das análises dos teores de compostos fenólicos.......................36

5. Síntese microbiana estimada a partir da incorporação de ${ }^{32} P$ (em mg $N$ incorporado por g de MS incubada)...

6. Resultado da média da produção de gases sem e com PVPP para lag time (horas), potencial ( $\mathrm{ml} \cdot \mathrm{g}^{-1} \mathrm{MS}$ ) e degradabilidade (g. $\left.\mathrm{kg}^{-1} \mathrm{MS}\right)$

7. Resultado da média da produção de gases sem e com PVPP para G48 e G96 horas

8. Resultado da média da produção de gases sem e com PVPP para Relação 1 e Relação 2

9. Correlações entre compostos fenólicos e parâmetros de produção de gases.

10. Média das constantes (c) do modelo $p=a+b\left(1-e^{-c t}\right)$ de degradabilidade, das frações prontamente solúveis (A) e não solúveis fermentáveis (B), das degradabilidades potenciais (Pot), e efetivas a uma taxa de passagem de $2 \% \cdot h^{-1}$ (Ef2), dos substratos testados 
11. Correlações entre compostos fenólicos e parâmetros de

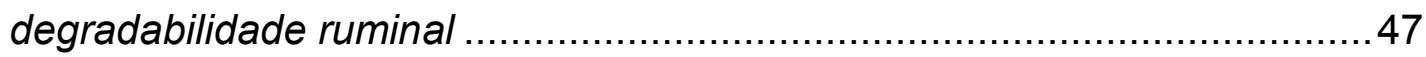




\title{
Determinação de taninos em plantas com potencial forrageiro para ruminantes
}

\author{
Autor: EDUARDO FERNANDO NOZELLA \\ Orientadora: Profa. Dra. DORINHA MIRIAM SILBER SCHMIDT VITTI
}

\section{RESUMO}

Os objetivos deste estudo foram determinar os teores de compostos fenólicos em plantas com potencial forrageiro através de análises químicas, e avaliar o efeito desses compostos através de técnicas in vitro (crescimento microbiano e produção de gás) e degradabilidade ruminal in situ. Amostras de plantas forrageiras, coletadas de vários locais, foram secas a $40^{\circ} \mathrm{C}$ e analisadas quanto ao teores de fenóis totais, taninos totais e taninos condensados. As plantas analisadas apresentaram grande variação quanto aos teores de taninos totais $\left(6,86\right.$ a 194,19 g. $\left.\mathrm{kg}^{-1} \mathrm{MS}\right)$, mostrando que algumas podem trazer prejuízo aos ruminantes. Diferentes valores de nitrogênio incorporado pelos microrganismos ruminais foram obtidos (0 a $8,92 \mathrm{mg} \mathrm{N}^{-1} \mathrm{~g}^{-1} \mathrm{MS}$ ) através da técnica de incorporação de radiofósforo $\left({ }^{32} \mathrm{P}\right)$. A utilização do PVPP em associação com esse método não apresentou bons resultados. O volume de gases produzidos em fermentação in vitro foi negativamente relacionado ao conteúdo de taninos $(r=-0,56 ; P<0,01)$. A adição do PVPP resultou em melhora na produção de gases apenas para o angico e jurema preta $(P<0,01)$. Os valores de degradabilidade efetiva, obtidos através da técnica in situ, variaram 
de 26 a $70 \%$, mostrando o potencial forrageiro de algumas destas plantas. Os coeficientes de correlação $(r)$ entre os teores de taninos e os parâmetros do modelo de degradabilidade ruminal foram de $-0,59(\mathrm{P}<0,01)$ para a taxa de degradação (c) e -0,39 $(P<0,05)$ para a degradabilidade efetiva $\left(2 \% \cdot h^{-1}\right)$. Estes resultados indicam o efeito adverso dos taninos na degradabilidade ruminal. As metodologias utilizadas possibilitaram identificar o efeito tóxico dos taninos aos ruminantes e selecionar plantas taniníferas que possuem potencial forrageiro. $O$ uso do PVPP não foi adequado para indicar os efeitos adversos dos fenóis em técnicas in vitro. 


\title{
Determination of tannin in plants with potential as forage for ruminants
}

\author{
Author: EDUARDO FERNANDO NOZELLA \\ Adviser: Prof. Dr. DORINHA MIRIAM SILBER SCHMIDT VITTI
}

\section{SUMMARY}

The objectives of this study were to determine the phenolic contents in different plants and to evaluate the effect of these compounds using in vitro techniques (microbial growth and gas production) and in situ rumen degradability. Samples of plants were collected from different places and they were dried at $40^{\circ} \mathrm{C}$ and analyzed for total phenols, total tannins and condensed tannins. The analyzed plants showed great variation on total tannin contents (6.86 to $194.19 \mathrm{g.kg}^{-1} \mathrm{DM}$ ). Microbial $\mathrm{N}$ synthesis was obtained (0 to $8,92 \mathrm{mg}$ $\left.\mathrm{N} . \mathrm{g}^{-1} \mathrm{DM}\right)$ by radiophosphate $\left({ }^{32} \mathrm{P}\right)$ incorporation technique. The use of PVPP in association with this method did not show good results. The volume of gas production was negatively related to tannin contents $(r=-0.56 ; P<0.01)$. The addition of PVPP resulted in better gas production for angico and jurema preta $(P<0.01)$. The effective degradability values varied from 26 to $70 \%$, showing the potential as forage of some of those plants. The correlation coefficient $(r)$ between tannin and rumen degradability parameters were $-0.59(P<0.01)$ for degradation rate $(c)$ and $-0.39(P<0.05)$ for effective degradability $\left(2 \% . h^{-1}\right)$. These results showed the adverse effect of tannin on rumen degradability. The methods used allowed to evaluate the toxic effects of tannin to ruminants. The 
use of PVPP on in vitro techniques was not suitable to indicate the different effects of phenolics in vitro. 


\section{INTRODUÇÃO}

A falta de alimentos volumosos para os rebanhos bovinos, caprinos e ovinos, durante o período de baixa precipitação pluviométrica, principalmente em zonas áridas e semi-áridas, é uma realidade que se repete todos os anos no Nordeste brasileiro e em outras regiões. Isto reflete a baixa produtividade na exploração de ruminantes, causando fortes transtornos econômicos, gerando aflição e apreensão para os pecuaristas, além de causar sérios problemas sociais.

O interior do Nordeste apresenta várias sub-regiões: agreste, cariris, seridó, curimataú e sertão, perfazendo o semi-árido nordestino. Nestas áreas, a vegetação predominante é a caatinga, que se caracteriza por apresentar, geralmente, plantas de baixo ou médio porte (herbáceo-arbustivo-arbóreo), xerófilas, e em sua maior parte, caducifólias, com predominância de leguminosas.

Muitas dessas forrageiras, que são usadas na alimentação de ruminantes, possuem alto teor de proteína bruta (160 g. $\mathrm{kg}^{-1} \mathrm{MS}$ ), mas apresentam baixa digestibilidade, como a Mimosa tenuiflora. Estas plantas podem apresentar altos níveis de fatores antinutricionais, principalmente taninos.

O conteúdo de taninos nas plantas pode variar de acordo com as condições climáticas e geográficas. Os taninos apresentam uma composição química variada, sendo, muitas vezes, pouco conhecida. $O$ efeito desses compostos inclui a inibição da fermentação no rúmen, pela ligação a proteínas e 
fibras, tornando-as resistentes à digestão, ou indiretamente, pela ligação com enzimas digestivas, prevenindo sua ação catalítica. Compostos como polietileno glicol (PEG) e polivinilpoli-pirrolidona (PVPP) podem formar complexos com os taninos, precipitando-os e minimizando os seus efeitos.

Vários são os métodos utilizados para a análise de fenóis totais e taninos totais, entretanto devido a essa variação na estrutura e composição torna-se difícil adequar os resultados analíticos aos efeitos nos animais. 


\section{OBJETIVOS}

Os objetivos do presente trabalho foram:

- determinar os teores de fenóis totais, taninos totais e taninos condensados em plantas forrageiras através de métodos químicos;

- validar técnicas in vitro e in situ para o estudo dos efeitos detrimentais dos taninos e relacionar com os teores de compostos fenólicos, determinados quimicamente;

- investigar o uso polivinilpoli-pirrolidona (PVPP) para minimizar os efeitos adversos dos taninos na digestibilidade e fermentabilidade das forragens tropicais.

Através desses métodos utilizados (in vitro e in situ), diferentes plantas

foram coletadas em vários locais e avaliadas quanto ao seu potencial para a alimentação animal. 


\section{REVISÃO DE LITERATURA}

\subsection{Taninos: bioquímica e propriedades nutricionais}

\subsubsection{Definição e ocorrência}

Os fenóis comuns em plantas não são considerados tóxicos em quantidades e condições normais, com exceção dos fenóis poliméricos denominados taninos, que possuem a habilidade de complexar e precipitar proteínas de soluções aquosas (Salunkhe et al., 1990).

Os taninos pertencem a um grupo de compostos fenólicos provenientes do metabolismo secundário das plantas (Butler et al., 1984) e são definidos como polímeros fenólicos solúveis em água que precipitam proteínas (Haslam, 1989). Taninos são polifenóis de ocorrência natural, em plantas, que exercem grande influência no valor nutritivo de forragens. Os taninos apresentam alto peso molecular, entre 500 a 3000 (Mangan, 1988) e contêm grupos hidroxilafenólicos em quantidade suficiente para permitir a formação de ligações cruzadas estáveis com proteínas (Deshpande et al., 1986).

$\mathrm{Na}$ forma não oxidada, os taninos reagem com as proteínas através de pontes de hidrogênio e/ou ligações hidrofóbicas. Quando oxidados, os taninos se transformam em quinonas, as quais formam ligações covalentes com alguns grupos funcionais das proteínas, principalmente os grupos sulfidrícos da cisteína e ع-amino da lisina (Sgarbieri, 1996). 
Os taninos são caracterizados pela sua capacidade de se combinar com proteínas da pele animal inibindo a putrefação, processo este conhecido como curtimento do couro (Deshpande et al., 1986). Esses compostos também são considerados potentes inibidores de enzimas devido à complexação com proteínas enzimáticas (Naczk et al., 1994).

Os taninos são amplamente distribuídos dentro do reino vegetal, sendo comuns tanto em espécies gimnospermas como angiospermas. Dentro das angiospermas, os taninos são mais comuns nas dicotiledôneas do que nas monocotiledôneas. Algumas famílias de dicotiledôneas ricas em taninos são as leguminosae, anacardiaceas, combretaceas, rhizoporaceae, mirtacea, polinaceae (Cannas, 1999).

Os taninos são encontrados principalmente nos vacúolos das plantas. Nestes locais eles não interferem no metabolismo da planta, somente após lesão ou morte das plantas eles agem e têm metabolismo eficiente (Cannas, 1999).

\subsubsection{Química e estrutura dos taninos}

Os taninos são classificados em dois grupos: 1) taninos hidrolisáveis, que, após hidrólise, produzem carboidratos e ácidos fenólicos; e 2) taninos condensados ou não hidrolisáveis, que são resistentes à hidrólise, e são oligômeros do grupos flavan-3-ols ou flavan 3,4-diols (Salunkhe et al., 1990).

Os taninos hidrolisáveis são unidos por ligações éster-carboxila, sendo prontamente hidrolisáveis em condições ácidas ou básicas (Hagerman \& Butler, 1981). A unidade básica estrutural desse tipo de tanino é um polyol, usualmente D-glucose, com seus grupos hidroxilas esterificados pelo ácido gálico (galotaninos) ou pelo ácido hexadihidroxifênico (elagitaninos) (Figura 1). 
Os taninos hidrolisáveis (TH) são encontrados em abundância em folhas, frutas, vagens de dicotiledônea, mas não têm sido detectados em monocotiledôneas (Lewis \& Yamamoto, 1989).

Os taninos condensados (TC) ou proantocianidinas são constituídos por unidades flavanol: flavan-3-ols (catequina) ou flavan 3,4-diols (leucoantocianidina). Eles estão presentes em maior quantidade nos alimentos normalmente consumidos (Deshpande et al., 1986; Salunkhe et al., 1990). Os TC podem conter de duas a cinquenta unidades flavanóides; possuem estruturação complexas; são resistentes à hidrólise, mas podem ser solúveis em solventes orgânicos aquosos, dependendo de sua estrutura. A Figura 2 ilustra a estrutura química dos taninos condensados.<smiles></smiles>

Figura 1. Estrutura química de tanino hidrolisado 


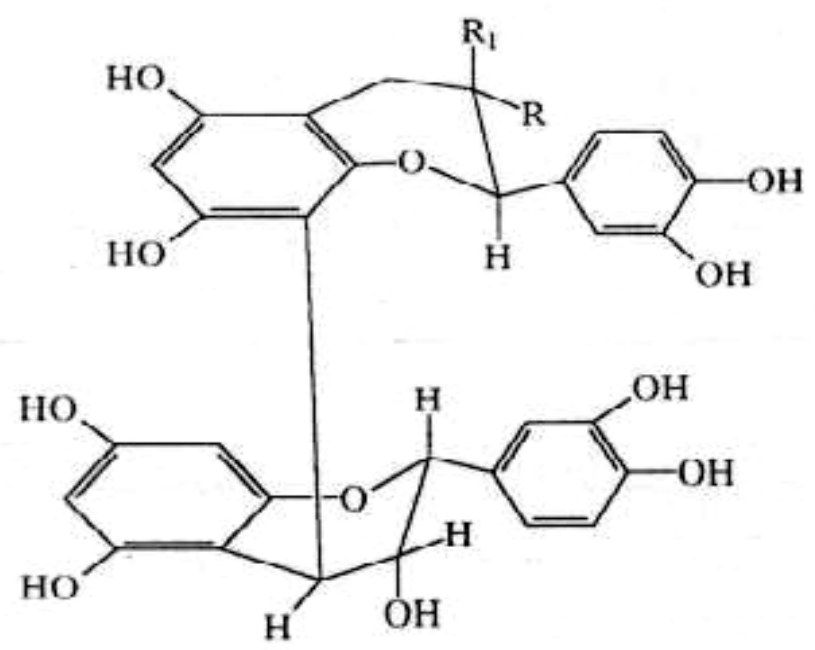

Figura 2. Estrutura química de tanino condensado

\subsubsection{Função dos taninos nas plantas}

Os taninos ocorrem em uma ampla variedade de plantas sendo este composto secundário considerado como um dos meios de defesa da planta contra fungos patogênicos, bactérias, vírus (Takechi et al., 1985) e contra ataques de insetos e herbívoros (Prince \& Butler, 1980; Katoh et al., 1989; Temmink et al., 1989). Boughdad et al. (1986) mostraram que o desenvolvimento de insetos e larvas foram reduzidos na presença de alto conteúdo de tanino. Porém, em trabalhos realizados por Coley (1983) e Martin et al. (1987) não foi observado nenhum efeito.

Metabólicos secundários, como flavanóis e antocianidinas, estão envolvidos no papel de atração de polinizadores e dispersão de sementes (Prince \& Butler, 1980).

Taninos previnem uma degradação rápida da planta no solo (Bunn, 1988), causando um aumento de nutrientes que serve como estoque para a planta no próximo período de vegetação (Synge, 1975). 
Há controvérsias em relação à função fisiológica dos taninos na planta. Green \& Corcoran (1975) suspeitavam que os taninos pudessem funcionar como reguladores de crescimento em plantas. O aumento da ocorrência de taninos em células periféricas e o aumento do conteúdo de tanino por aumento da iluminação sugere um mecanismo de proteção contra o estresse causado pela luz solar (Salatino et al., 1988).

Segundo Getachew (1999) os taninos parecem ter um papel importante na proteção das plantas contra estresses ambientais, como baixa fertilidade do solo e seca.

\subsubsection{Taninos na nutrição animal}

Os taninos têm um importante papel na nutrição animal, podendo exercer efeitos adversos e/ou benéficos na utilização de nutrientes, na saúde e na produção animal.

O principal impacto dos taninos na nutrição animal deve-se à habilidade desses compostos em formar complexos com vários tipos de moléculas.

Além da capacidade dos taninos em precipitar proteína, eles também são capazes de interagir com outras macromoléculas, como carboidratos, membrana celular das bactérias e íons metálicos (Leinmüller \& Karl-Heinz, 1991).

Segundo Haslam (1996), a complexação dos taninos com a proteína é a base principal do efeito biológico. Essa complexação com a proteína é dependente de $\mathrm{pH}$ e, portanto, é reversível, e envolve ligações hidrofóbicas e pontes de hidrogênio. 
A interação entre taninos e proteínas é específica e depende da estrutura de ambos. Butler (1982) relacionou algumas características importantes das proteínas para a sua associação com os taninos.

- peso molecular: proteínas com alto peso molecular associam-se mais fortemente aos taninos;

- estrutura das proteínas: proteínas com estruturas mais abertas e flexíveis têm maior afinidade aos taninos. Por outro lado, proteínas globulares, que são mais compactas, possuem menor afinidade aos compostos fenólicos;

- ponto isoelétrico: a afinidade das proteínas aos taninos é maior no ponto isoelétrico da proteína, embora algumas proteínas se associem aos taninos em um amplo limite de $\mathrm{pH}$;

- conteúdo de prolina: as proteínas ricas em prolina, como as zeínas no milho e kafirina no sorgo, são lineares, uma vez que este aminoácido não se insere em uma estrutura em $\alpha$-hélice, assim, aumenta-se a superfície de contato do polipeptídio, com maior probabilidade de reação.

Segundo revisão de Spencer et al. (1988), a estrutura e propriedade dos polifenóis são importantes para a formação do complexo tanino-proteína, sendo que três características devem ser consideradas:

- tamanho da molécula: moléculas maiores são mais eficazes na associação com proteínas;

- conformação flexível: quando a molécula sofre retração, facilita a ligação do polifenol a sítios das proteínas;

- solubilidade: uma relação inversa existe entre a força de associação com a proteína e a solubilidade em água do polifenol, com isso, baixa solubilidade favorece fortemente esta associação. 


\subsubsection{Efeitos benéficos dos taninos}

Muitos trabalhos citados na literatura mostram que quantidades moderadas de taninos condensados (10 a $40 \mathrm{~g} . \mathrm{kg}^{-1} \mathrm{MS}$ ) podem prevenir o timpanismo; aumentar o fornecimento de proteína "by-pass" (proteína não degradada) para digestão no intestino delgado, e melhorar a utilização de aminoácidos essenciais da dieta (Brandes \& Feitas, 1992).

As proteínas solúveis da planta libertadas no rúmen produzem espumas que retém os gases e, conseqüentemente causam um aumento considerável daquele órgão. Os taninos, formando um complexo com essas proteínas solúveis, podem estar envolvidos na prevenção de timpanismo (Getachew, 1999).

O complexo tanino-proteína é formado a partir da mastigação de plantas que contém taninos. Este é estável sobre uma variação de $\mathrm{pH}$ entre 3,5 - 7,0. Isso faz com que a proteína fique protegida da hidrólise microbiana e deaminação no rúmen, uma vez que o pH deste órgão encontra-se geralmente nessa faixa, e aumenta a proporção de proteína do alimento disponível para a digestão e absorção pós-rúmen (Aerts et al., 1999).

\subsubsection{Efeitos adversos}

Há poucos estudos da degradação de taninos pela microflora ruminal. Alguns dados sugerem que o ácido gálico e oligoflavanóis podem ser degradados pelos microrganismos do rúmen (Deschamps \& Lebeault, 1985; Deschamps, 1985; Murdiatu et al., 1987). Os oligoflavanóis inibem as atividades proteolíticas, ureolíticas e celulolíticas do rúmen (Lohan et al., 1983). Verificouse que a atividade da celulase in vitro variou de 2 a 70 \% com a adição (ao 
meio de incubação) de extratos de compostos fenólicos de diversas plantas (Mueller-Harvey et al., 1987).

Os efeitos adversos dos taninos incluem: redução no consumo; baixa digestibilidade; inibição de enzimas digestivas; perda de proteínas endógenas, e efeitos sistêmicos como resultado de produtos degradados de $\mathrm{TH}$ no trato digestivo (Getachew et al., 2000).

A baixa aceitabilidade de algumas espécies de plantas é relacionada à concentração de taninos - aproximadamente 5 \% (McNaughton, 1987).

Os taninos podem reduzir a ingestão por diminuição da aceitabilidade e por afetar negativamente a digestão. A aceitabilidade é reduzida por causa dos taninos serem adstringentes. Adstringência é a sensação causada pela formação de complexos entre os taninos e glicoproteína salivar, e pode aumentar a salivação e diminuir a aceitabilidade (Reed, 1995). Quanto menor a aceitabilidade, menor a ingestão de alimento e, assim, a produtividade animal.

Os TH são tóxicos para os ruminantes. Observou-se que animais alimentados com folhas de carvalho diminuem a produtividade e o aumento da ingestão causa toxidade devido à presença de TH (Makkar et al., 1988). O metabolismo microbiano e a digestão gástrica convertem os $\mathrm{TH}$ em produtos metabólicos de baixo peso molecular, que são absorvidos pelo organismo, sendo que alguns destes compostos são tóxicos (Cannas, 1999). Em animais monogástricos ou em ruminantes, TH como ácido tânico pode ser absorvido pelo trato gastrintestinal intacto ou modificado e pode causar necrose nos rins e no fígado (Zhu et al., 1995).

Os taninos condensados (TCs) não são absorvidos pelo trato digestivo, podendo causar danos na mucosa do trato gastrintestinal, diminuindo a absorção de nutrientes como, por exemplo, a redução da absorção de aminoácidos essenciais - metionina e lisina (Cannas, 1999). 
Segundo Van Hoven (1984), os TCs têm uma influência altamente negativa na digestibilidade da matéria seca, comparado com o ácido de tânico que é um tanino hidrolisável. Foi observado que os taninos inibem fortemente as enzimas digestivas em ensaios in vitro (Mehansho et al. $^{1}$ citados por Getachew, 1999).

\subsubsection{Toxidade dos taninos aos microrganismos do rúmen e efeitos em parasitos}

Os TCs não parecem ser degradados pelos microrganismos do rúmen (Makkar et al., 1995) e sua absorção não ocorre no trato gastrintestinal (Terrill et al., 1994).

A toxidade dos taninos aos microrganismos do rúmen tem sido descrita para várias espécies de bactérias, como Streptococcus bovis, Butyrivibrio fibrisolvens, Fibrobacter succinogenes, Ruminobacter amylophilus (Young \& Paterson, 1980; Cannas, 1999).

Os mecanismos que causam essa toxicidade incluem: a) inibição de enzimas e deprivação de substrato; b) ação nas membranas; c) deprivação de íons metálicos (Scalbert, 1991).

Tem sido verificado, que alguns animais que consomem plantas taniníferas, apresentam resistência a parasitos internos (Getachew, 1999). Um efeito depressivo sobre o número de ovos/g de nematóides nas fezes foi indicado (Niezen et al., 1993). Entretanto, os mecanismos envolvidos não estão esclarecidos ainda. Makkar et al. (1995) observaram in vitro também efeito significativo na redução do número de protozoários do rúmen.

\footnotetext{
${ }^{1}$ MEHANSHO, H.; ANN, D.K.; BUTLER, L.G.; ROGLER, J.C.; CARLSON, D.M. Introduction of prolinerich proteins in hamster salivary glands by isoproterenol treatment and an unusual growth inibition by tannins. Journal of Biological Chemistry, v.262, p.123-144, 1987.
} 


\subsubsection{Métodos para reduzir os efeitos antinutricionais dos taninos}

O principal impacto dos taninos na nutrição animal é devido à habilidade de formar complexos com vários tipos de moléculas.

Além da habilidade dos taninos em precipitar proteína, eles também são capazes de interagir com outras macromoléculas, como carboidratos, membrana celular das bactérias e íons metálicos (Leinmüller \& Karl-Heinz, 1991).

Em numerosos estudos, a alta afinidade dos taninos por polímeros sintéticos, como polietileno glicol (PEG) ou polivinil polipirrolidona (PVPP), tem sido relatada (Oh et al., 1980; Hagerman \& Butler, 1981).

O uso do PVPP não interfere no processo de fermentação. Com isso, é possível estudar, in vivo ou in vitro, a ação desses polímeros para reduzir ou cancelar os efeitos dos taninos (Khazaal \& Ørskov, 1994).

A capacidade do PVPP em formar complexos com os taninos tem sido aplicada para a extração e a quantificação de taninos (Makkar et al., 1993).

Os efeitos dos taninos no valor nutritivo de plantas podem ser estudados com o uso de agentes complexantes como o PEG, que se complexa fortemente com os taninos e inibe sua ação (Getachew et al., 2000).

O efeito da adição de PEG na digestibilidade e fermentabilidade in vitro da fração fibra de seis leguminosas tropicais foi investigado (Longland et al., 1994). Os resultados mostraram que taninos condensados podem reduzir a digestibilidade da fibra e alterar a cinética da fermentação de leguminosas. Esses efeitos podem ser minimizados ou eliminados pela adição do PEG.

Outros métodos para reduzir os efeitos antinutricionais dos taninos são além disso indicados: 
- remoção física dos taninos por extração ou moagem: através do uso de solução aquosa de álcalis ou mesmo água, na qual as plantas ou sementes são colocadas por algum tempo. A moagem das plantas ou sementes é um processo que pode auxiliar a extração dos taninos, antes do tratamento com líquido (Butler, 1989);

- adição de agentes como metionina ou colina na dieta de aves aliviam o efeito de depressão no crescimento causado por produtos secundários do metabolismo dos taninos (Rayudu et al., 1970);

- inativação dos taninos por tratamento com hidróxido ou carbonato de cálcio (Salunkhe et al., 1990);

- seleção de variedades de plantas com teores mais baixos de taninos (Price \& Butler, 1980).

\subsubsection{Métodos de quantificação dos taninos}

A quantidade e o tipo de tanino sintetizado pelas plantas variam consideravelmente, dependendo da espécie da planta; dos cultivares; tecido; estágio de desenvolvimento e condições ambientais. Portanto, os estudos dos efeitos nutricionais dos taninos, em animais, requerem a quantificação dos taninos presentes na dieta. Devido à complexidade dos taninos, vários métodos têm sido desenvolvidos para a sua quantificação. Nenhum deles, porém, é completamente satisfatório.

Os métodos mais citados na literatura para a determinação de taninos em forragens são os métodos colorimétricos. 
As preparações das amostras têm grande influência na determinação de taninos e na relação com os polifenóis das plantas (Reed, 1995).

Segundo Haslam² citado por Reed (1995), a secagem é um dos meios de conservar o material. A temperatura de secagem deve ser maior que $40^{\circ} \mathrm{C}$, para evitar oxidação pela paralisação da atividade enzimática, e menor que $60^{\circ} \mathrm{C}$ para evitar prejuízos com a fermentação e polimerização.

As amostras para determinações de taninos devem ser de preferência amostras frescas e transportadas em baixa temperatura (no gelo ou dióxido de carbono) e devem ser secas ao ar (na sombra) ou secas em estufa a uma temperatura menor que $40^{\circ} \mathrm{C}$ (Mueller-Harvey, 2001).

Outros métodos para a determinação de taninos incluem HPLC (cromatografia líquida de alta resolução), gravimetria, métodos de ligação e precipitação com proteínas. A dificuldade dessas análises e suas interpretações ocorre porque a maioria dos métodos mede taninos não em termos absolutos, mas em relação a padrões, por exemplo, ácido tânico e ácido gálico.

A extração dos taninos dos tecidos vegetais é difícil porque eles podem estar ligados a carboidrato, proteína, parede celular ou são insolúveis (Salunkhe et al., 1990).

Os métodos gravimétricos foram desenvolvidos para tentar se resolver o problema do uso de padrões (Makkar et al., 1993), mas também dependem da eficiência da extração.

Estudos dos efeitos dos taninos na fermentação ruminal e na síntese microbiana tem sido restritos a leguminosas de regiões temperadas.

Há atualmente uma grande tendência no uso de técnicas in vitro, como a produção de gases, para avaliar forragens e efeitos dos taninos na fermentação no rúmen (Getachew, 1999).

\footnotetext{
${ }^{2}$ HASLAM, E Chemistry of vegetable tannins. Academic Press. New York, 1966.
} 


\subsection{Incorporação in vitro do ${ }^{32} \mathrm{P}$ e síntese microbiana}

Algumas técnicas foram propostas com o intuito de determinar as quantidades de matéria orgânica dos alimentos fermentadas pelos microrganismos do rúmen. Elementos marcadores destes organismos como o 2.6-ácido diaminopimelínico (Hutton et al., 1971), ou o radioenxôfre $\left({ }^{35} \mathrm{~S}\right.$ ) marcando o enxôfre (S) microbiano (Beever et al., 1974), foram utilizados com esta finalidade. Entretanto, as possíveis incorporações de peptídeos e aminoácidos extracelulares, assim como as dificuldades laboratoriais de métodos utilizando o ${ }^{35} \mathrm{~S}$ (Walker \& Nader, 1968; Nikolic, et al., 1975), tornaram necessária a utilização de outros elementos químicos como marcadores.

A escolha do fósforo $\left({ }^{32} \mathrm{P}\right)$ como elemento marcador da atividade microbiana, baseou-se no princípio de que os compostos fosforilados como os nucleotídeos não conseguem penetrar nas células microbianas. Os ácidos nucléicos fosforilados representam a maioria dos ácidos nucléicos microbianos, tornando aceitável que todo o $\mathrm{P}$ microbiano é derivado de compostos fosforilados extracelulares (Van Nevel \& Demeyer, 1977).

O uso de radioisótopos tem mostrado resultados satisfatórios em pesquisas relacionadas com a utilização de fósforo pelos microrganismos do rúmen. Através da coleta de amostra de líquido de rúmen pode-se medir a taxa de incorporação de fósforo radioativo $\left({ }^{32} \mathrm{P}\right)$ in vitro, avaliando desta maneira a atividade microbiana (Vitti \& Silva Filho, 1985). O método baseia-se na relação entre a incorporação do fósforo na matéria microbiana e a síntese de proteína, utilização de amônia ou produção de ácidos graxos voláteis, em períodos de incubações curtos usando ${ }^{32} \mathrm{P}$ como marcador (Van Nevel \& Demeyer, 1977).

Segundo Van Nevel \& Demeyer (1977), a atividade específica do ${ }^{32} \mathrm{P}$ extracelular $\left(A E_{e}\right)$, em dpm/mg, é dada pela relação entre a contagem da porção sobrenadante, ou extracelular (em desintegrações por minuto, dpme) e 
a quantidade de $\mathrm{P}$ extracelular total $\left(\mathrm{P}_{e}\right)$ na amostra encaminhada para a contagem, em mg, ou seja,

$$
A E_{e}=d p m_{e} / P_{e}
$$

A quantidade de $P$ incorporada à massa microbiana $\left(P_{i}\right)$, em $\mathrm{mg}$, é dada pela relação entre as contagens no material precipitado $\left(d p m_{i}\right)$ e a atividade especifica extracelular $\left(A E_{e}\right)$ :

$$
P_{i}=d p m_{i} / A E_{e} .
$$

Van Nevel \& Demeyer (1977), chegaram a um valor de $8.37 \pm 0.75$ para a relação $\mathrm{N}$ : $\mathrm{P}$ na massa microbiana dos animais e substratos por eles estudados, possibilitando a utilização deste valor na multiplicação da quantidade de $\mathrm{P}$ incorporado, para o cálculo do total de nitrogênio incorporado na massa microbiana $\left(\mathrm{N}_{\mathrm{i}}\right)$.

Estudos in vitro com o uso de ${ }^{32} \mathrm{P}$, foram feitos para medir a síntese microbiana (Vitti et al., 1985). A adição de diferentes quantidades de ácido tânico ao meio de incubação afetou a atividade microbiana, verificando-se correlação negativa entre a concentração de ácido tânico e a atividade dos microrganismos.

\subsection{Produção de gases in vitro}

A técnica de produção de gases é baseada na simulação das fermentações ruminais em frascos de vidro inoculados com microrganismos ruminais. A produção de gases pode ser medida em tempos pré-determinados 
para a descrição da cinética de fermentação e, após 96 horas de incubação, o material residual é filtrado para a determinação da matéria orgânica digerida (MOD) (Theodorou et al., 1994).

Algumas metodologias foram criadas para a utilização da técnica de produção de gases, com o uso de seringas de vidro, ou garrafas, ou ainda utilizando aparelhos mais sofisticados. A base desta técnica é a mesma, independente da metodologia usada. Uma certa quantidade de amostra é colocada em um recipiente hermeticamente fechado, contendo uma solução tampão, uma solução de macro e microminerais e um inóculo (microrganismos ruminais) (Bueno, 1998).

A técnica de produção de gases in vitro, para estudos da ação de fatores antinutricionais, têm tido várias vantagens sobre outros métodos como a digestibilidade in situ ou in vitro que são baseados na determinação gravimétrica de resíduos (Getachew et al., 1998).

Essa técnica tem sido utilizada por muitos pesquisadores, com a finalidade de estudar o efeito de algumas forrageiras que possuem fatores antinutricionais na fermentação ruminal e digestibilidade da matéria seca. Ela é útil para se testar o uso de produtos químicos disponíveis comercialmente como PEG ou PVPP que têm afinidade de se complexarem com os taninos.

A técnica in vitro de produção de gases demonstra a cinética fermentativa e o perfil de degradação dos alimentos. Os parâmetros comparados são "lag time" (LAG), degradabilidade in vitro da MS (DEG) e produção de gases. Bueno et al. (2001), sugeriram duas novas relações entre a produção de gases após 48 h (G48), 96 h (G96) e a potencial de produção de gases (POT), que são G48 e G96 (REL 1) e entre G96 e POT (REL 2).

Esses dois parâmetros (REL 1 e REL 2) foram incluídos para melhor entender a cinética fermentativa. Supondo um tempo médio de retenção de rúmen não superior a $50 \mathrm{~h}$, seria desejável que os nutrientes digestíveis fossem 
digeridos nesse intervalo. Assim REL 1 representa a proporção da quantidade de gases produzidos durante as primeiras $48 \mathrm{~h}$ em relação ao tempo total do ensaio (96 h) e quanto mais próximo de 1 , indica que melhor foi 0 aproveitamento dos nutrientes disponíveis. A REL 2 representa a proporção do potencial de produção de gases que foi conseguida em 96 horas. Em longo período de incubação, a fermentação dos alimentos deve atingir o seu potencial, com isso a relação deve ser mais próxima de 1 . Caso isso não ocorra, o período de incubação do ensaio não foi suficiente ou a taxa de fermentação do alimento é tão baixa que o modelo matemático não consegue ajustar os dados de modo satisfatório.

\subsection{Degradabilidade ruminal in situ}

A técnica in situ proposta por Ørskov \& McDonald (1979), foi fundamentada nas taxas de degradação dos alimentos suspensos em sacolas de nylon no rúmen dos animais por determinados períodos de tempo. Através de um modelo matemático, é possível estimar a degradabilidade potencial do alimento em estudo.

Esta metodologia foi amplamente aplicada no sistema inglês de avaliação dos alimentos (A.F.R.C. 1993), que além das estimativas das quantidades de proteína bruta e energia metabolizável, pôde determinar os conteúdos de proteína efetivamente degradada no rúmen e de proteína digestível não degradada no rúmen.

Segundo Khazaal et al. (1993), os resultados da avaliação da degradabilidade de plantas contendo taninos in situ no rúmen podem ser influenciados pelo efeito da diluição do grande volume do rúmen em relação ao pequeno volume da sacolinha. 


\section{MATERIAL E MÉTODOS}

\subsection{Local}

O presente trabalho foi realizado no Laboratório de Nutrição Animal (LANA) do Centro de Energia Nuclear na Agricultura (CENA/USP), Piracicaba, SP.

\subsection{Substratos utilizados e preparo das amostras para análises}

Os substratos utilizados são indicados na Tabela 1. Na coleta de amostras, foram selecionadas plantas de vários locais, com altura de 1,5 a $2 \mathrm{~m}$. Coletaram-se folhas e caules com um máximo de $0,5 \mathrm{~cm}$ de espessura.

Após o corte, as plantas foram picadas e secas em estufa a $40^{\circ} \mathrm{C}$, com circulação de ar forçada e foram mantidas até peso constante. Seguiu-se a moagem das amostras em moinho Wiley, usando peneiras de $2 \mathrm{~mm}$ (técnica in situ), $1 \mathrm{~mm}$ (análises químicas e técnicas in vitro) e 0,25 mm (compostos fenólicos). O material moído foi armazenado em temperatura ambiente, num local arejado e escuro, para evitar a degradação dos taninos. 
Tabela 1: Nomes vulgares, científicos, classificação (familías) das plantas utilizadas e locais de coletas

\begin{tabular}{llll}
\hline Nome vulgar & Nome cientifico & Família & Local \\
\hline Alfafa & Medicago sativa L. & Leguminosae & $\mathrm{CENA}^{1}$ \\
Angico & Anadenanthera macrocarpa (Benth.) Brenan. & Leguminosae & $\mathrm{PE}^{2}$ \\
Aroeira & Myracrodruon urundeuva Engl. & Anacardiaceae & $\mathrm{PE}^{2}$ \\
Feijão bravo & Capparis flexuosa L. & Capparaceae & $\mathrm{PE}^{2}$ \\
Feijão guandu & Cajanus cajan $\mathrm{L}$. & Leguminosae & $\mathrm{UNESP}^{3}$ \\
Gliricídia & Gliricidia sepium & Leguminosae & $\mathrm{IZ}^{4}$ \\
Jurema preta & Mimosa tenuiflora Benth & Leguminosae & $\mathrm{PE}^{2}$ \\
Leucena & Leucaena leucocephala (Lam.) de Wit & Leguminosae & $\mathrm{PE}^{2} \mathrm{e} \mathrm{IZ}^{4}$ \\
Malva branca & Sida cordifolia L. & Malvaceae & $\mathrm{PE}^{2}$ \\
Mela-bode & Herissantia crispa L. & Malvaceae & $\mathrm{PE}^{2}$ \\
Moleque duro & Cordia leucocephala Moirc. & Boraginaceae & $\mathrm{PE}^{2}$ \\
Sesbânia & Sesbania sesban & Leguminosae & $\mathrm{IZ}^{4}$ \\
\hline
\end{tabular}

${ }^{1}$ Centro de Energia Nuclear na Agricultura

${ }^{2}$ Região do Agreste de Pernanbuco

${ }^{3}$ Faculdade de Medicina Veterinária e Zootecnia de Botucatu

${ }^{4}$ Instituto de Zootecnia de Nova Odessa

\subsection{Análises químicas}

Para as análises bromatológicas, seguiram-se as recomendações da A.O.A.C. (1995). Os teores em fibra em detergente neutro (FDN), fibra em detergente ácido (FDA) e lignina em detergente ácido (LDA) foram determinados (Van Soest \& Wine 1967). O conteúdo de fenóis totais e taninos foram analisados através do método Folin-Ciocalteu e os taninos condensados (proantocianidina) pelo método de Porter et al. ${ }^{3}$ citados por Makkar (2000).

3 POTER, L.J.; HRSTICH, L.N.; CHAN, B.G. The conversion of proanthocyanidins and prodelphinidins to cyanidin and delphinidin. Phytochemistry, v.25, p.223-230, 1986. 


\subsubsection{Determinação de fenóis totais, taninos e taninos condensados}

\subsubsection{Extração das frações solúveis}

O método para determinação de fenóis totais é útil para se conhecer a eficiência da extração desses compostos em solvente. Esta metodologia pode ser acoplada ao uso de uma matriz insolúvel, como o PVPP, para determinação dos taninos.

Foram pesados $200 \mathrm{mg}$ de amostra moída $(0,25 \mathrm{~mm})$, em becker de 30 $\mathrm{ml}$ e adicionados $10 \mathrm{ml}$ de solução de acetona $70 \%$. As amostras foram submetidas a ultra-som (KERRY ULTRASONICS LIMITED - MODELO 250), em água contendo gelo por um período de 20 minutos. Após o tratamento com ultra-som, as amostras foram centrifugadas por 10 minutos a $4^{\circ} \mathrm{C}$ a $3000 \mathrm{~g}$ (centrífuga IEC CENTRA - 7R). O sobrenadante foi coletado e conservado no gelo.

\subsubsection{Curva padrão para compostos fenólicos e taninos}

A curva padrão para fenóis e taninos foi feita com uma solução padrão de ácido tânico - 0,1 mg. $\mathrm{ml}^{-1}$ (Tabela 2).

\subsubsection{Determinação de fenóis totais}

Para a análise de fenóis e taninos, várias diluições das amostras foram testadas, dependendo do teor desses compostos. A melhor diluição foi aquela em que os resultados ficaram na faixa mediana da curva padrão. 
Tabela 2: Curva padrão do ácido tânico

\begin{tabular}{ccccc}
\hline Tubo & $\begin{array}{c}\text { Sol. Ácido } \\
\text { tânico }(\mu \mathrm{l})\end{array}$ & $\begin{array}{c}\text { Reagente } \\
\text { Folin Cioc. }(\mu \mathrm{l})\end{array}$ & $\begin{array}{c}\text { Sol. } \mathrm{Na}_{2} \mathrm{CO}_{3} \\
(\mathrm{ml})\end{array}$ & $\begin{array}{c}\text { Ácido tânico } \\
(\mu \mathrm{g})\end{array}$ \\
\hline T0 & 0 & 500 & 1,25 & 0 \\
T1 & 20 & 480 & 1,25 & 2 \\
T2 & 40 & 460 & 1,25 & 4 \\
T3 & 60 & 440 & 1,25 & 6 \\
T4 & 80 & 420 & 1,25 & 8 \\
T5 & 100 & 400 & 1,25 & 10 \\
\hline
\end{tabular}

Em tubos de ensaio foram adicionados: $50 \mu \mathrm{l}$ do sobrenadante referente a cada amostra (em duplicata), $450 \mu \mathrm{l}$ de água destilada, $250 \mu \mathrm{l}$ do reagente Folin Ciocalteu ( $1 \mathrm{~N}$ ) diluído (1:1) e 1,25 ml de carbonato de sódio (20 $\%)$. Os tubos foram agitados e após 40 minutos foi feita a leitura em um espectrofotômetro (DU - 64 BECKMAN), em absorbância de 725 nm. O teor de fenóis totais (FT) foi calculado em equivalente de ácido tânico, pela curva de calibração, e expresso com base na matéria seca.

\subsubsection{Determinação de taninos totais}

A determinação dos taninos baseia-se no fato de que o PVPP se liga a eles, portanto os taninos são precipitados.

Foram pesados $100 \mathrm{mg}$ de PVPP (SIGMA P-6755) em tubos de ensaio (um por amostra) e, nestes tubos, adicionados $1 \mathrm{ml}$ de água destilada e $1 \mathrm{ml}$ do extrato diluído. Após agitação, os tubos foram colocados em geladeira por 15 minutos e agitados novamente. Em seguida os tubos foram centrifugados a $3000 \mathrm{~g}$ por 10 minutos a $4^{\circ} \mathrm{C}$ (centrífuga IEC CENTRA - 7R) e o sobrenadante foi coletado. O sobrenadante deve conter apenas fenóis simples, uma vez que 
os taninos foram precipitados. $100 \mu \mathrm{l}$ do sobrenadante foram pipetados em tubos de ensaio (em duplicata), e aos tubos foram adicionados $400 \mu \mathrm{l}$ de água destilada, $250 \mu \mathrm{l}$ do reagente Folin Ciocalteu (1 N) diluído (1:1) e 1,25 ml de carbonato de sódio (20\%). Os tubos foram agitados e após 40 minutos foi feita a leitura em espectrofotômetro, em absorbância de $725 \mathrm{~nm}$. Determinou-se o teor de fenóis simples e por diferença entre fenóis e fenóis simples obteve-se a concentração de taninos totais (TT), que foi calculada em equivalente de ácido tânico.

\subsubsection{Determinação de taninos condensados}

Após diluições apropriadas do extrato das plantas, foram adicionados em tubos de ensaio $0,5 \mathrm{ml}$ do extrato diluído, $3 \mathrm{ml}$ de reagente butanol- $\mathrm{HCl}$ e $0,1 \mathrm{ml}$ de reagente férrico, sendo posteriormente agitados. Foram colocadas bolinhas de gude na boca dos tubos contendo as amostras e do branco feito com a amostra sem diluição. Em seguida, os tubos foram colocados para aquecer em um banho-maria a $100^{\circ} \mathrm{C}$, por uma hora. Um branco de cada amostra (com e sem diluição) não foi aquecido.

Após esse período, os tubos foram esfriados e foram feitas as leituras através de espectrofotômetro em absorbância $550 \mathrm{~nm}$.

Os teores de taninos condensados (TC) foram expressos, como equivalente em leucocianidina, pela fórmula: (leitura $\times 78,26 \times$ fator de diluição)/\%MS. 


\subsection{Bioensaios}

Além das análises químicas, as técnicas de digestibilidade com sacolas de nylon; a produção de gases e a síntese microbiana in vitro foram utilizadas para avaliar os efeitos dos taninos presentes nos substratos.

Os animais utilizados, como doadores de líquido do rúmen e para a digestibilidade in situ, foram ovinos machos adultos, castrados, da raça Santa Inês e providos de cânula permanente de rúmen.

\subsubsection{Síntese microbiana}

A síntese microbiana foi medida in vitro, com o uso de fósforo radioativo $\left({ }^{32} \mathrm{P}\right)$.

Foram utilizados, para cada amostra, 6 tubos contendo 1 grama de MS. Em 3 tubos foi adicionado $1 \mathrm{~g}$ de PVPP por tubo. Também foram preparados 6 tubos sem substrato, sendo 3 com PVPP. A todos os tubos, foram adicionados $4 \mathrm{ml}$ de solução contendo $25 \mathrm{~g}$ de glucose, $3 \mathrm{~g}$ de bicarbonato de sódio, $16 \mathrm{ml}$ de líquido do rúmen (filtrado com duas gases) e $25 \mu \mathrm{l}$ de solução de radiofósforo, correspondendo a $0,1 \mu \mathrm{Ci}$ de ${ }^{32} \mathrm{P}$ por tubo.

Imediatamente após a adição do radiofósforo, em um dos três tubos de cada série (com e sem PVPP), foi adicionado $1 \mathrm{ml} \mathrm{de} \mathrm{H}_{2} \mathrm{SO}_{4} 18 \mathrm{~N}$, para a paralisação da atividade microbiana. Todos os tubos foram levados à incubadora a $38^{\circ} \mathrm{C}$ com saturação de gás carbônico por 8 horas. Após este tempo, a síntese microbiana foi interrompida pela adição de $1 \mathrm{ml}$ de $\mathrm{H}_{2} \mathrm{SO}_{4} 18$ $\mathrm{N}$.

Seguiu-se à centrifugação a $39.079 \mathrm{~g}$ (centrifuga RC2-B Sorvall Super Speed) durante 10 minutos e o sobrenadante foi separado. Um $\mathrm{ml}$ do 
sobrenadante foi transferido para frascos de contagem contendo água destilada $(19 \mathrm{ml}$ ) para contagem da radioatividade em cintilador líquido (BECKMAN - LS 5000 TA) pelo efeito Cerenkov (Nascimento Filho \& Lobão, 1977).

O precipitado foi lavado por quatro vezes (Gobbo et al., 2000) com

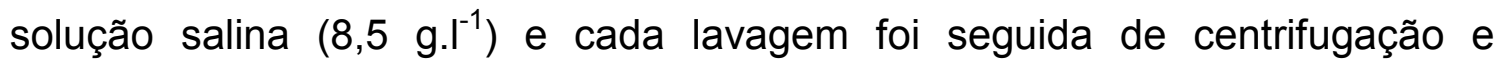
descarte do sobrenadante. Ao término das lavagens, os precipitados foram suspensos com $20 \mathrm{ml}$ de água destilada e colocados em cadinhos para as determinações de matéria seca e cinzas. Foi feita digestão das cinzas com ácido sulfúrico $(18 \mathrm{~N})$, durante 90 minutos.

Após a digestão, o material foi transferido para frascos de contagem e completado o volume com água destilada $(19 \mathrm{ml})$, para contagem da radioatividade presente, pelo efeito Cerenkov (Nascimento Filho \& Lobão, 1977).

\subsubsection{Determinação de fósforo inorgânico no sobrenadante}

O método utilizado para determinação do $\mathrm{P}$ no sobrenadante foi aquele descrito por Fiske \& Subbarow (1925). Neste método, a amostra é desproteinizada com ácido tricloroacético a $10 \%$. Da amostra desproteinizada, 2,5 $\mathrm{ml}$ foram colocados em tubo de ensaio e a estes foram adicionados $0,5 \mathrm{ml}$ de reagente molibdato e $0,2 \mathrm{ml}$ de solução de ácido aminonaftolsulfônico, e o volume final foi completado para $5 \mathrm{ml}$.

A leitura foi feita em fotocolorímetro, em absorbância de $660 \mathrm{~nm}$ (Vital Scientic, modelo VITALAB 10) contra água destilada. A partir das leituras, foi retirado o valor do branco e, para o cálculo de $P$, foi feito um padrão de valor conhecido (5 $\mathrm{mg} \%$ de fosfato). 


\subsubsection{Cálculos da incorporação microbiana}

Inicialmente foi calculada a atividade específica extracelular $\left(A E_{e}\right)$. Sendo esta variável encontrada através dos resultados de contagem da porção do sobrenadante das amostras $\left(A_{e-a m t}\right)$, da atividade do padrão $\left(A_{p}\right)$ que é uma solução contendo apenas o radiofósforo e a atividade do branco $\left(A_{g}\right)$ amostra contendo água destilada. Para a determinação da $A E_{e}$, os resultados obtidos das contagens das amostras e do padrão foram divididos pelas quantidades de fósforo determinadas no sobrenadante $(P)$, de acordo com a expressão:

$$
A E_{e}=\left(A_{e-a m t}-A_{g} / A_{p}-A_{g}\right) / P \times 100
$$

Após a determinação da $A E_{e}$, foram calculadas as quantidades de fósforo incorporado $\left(P_{i}\right)$ na porção precipitada das amostras. Para isto, foram realizadas as contagens do precipitado, obtendo-se a atividade específica do precipitado $\left(A_{i-a m t}\right)$ e também a atividade específica do padrão $\left(A_{p}\right)$ e do branco $\left(A_{g}\right)$ de maneira similar ao sobrenadante:

$$
P_{i}=\left(A_{i-a m t}-A_{g} / A_{p}-A_{g}\right) / A E_{e}
$$

A partir do cálculo das quantidades de $\mathrm{P}_{\mathrm{i}}$ na porção precipitada pode-se estimar as quantidades de microrganismos incorporados para cada substrato em estudo e detectar o efeito da adição do PVPP. Os resultados de $P_{i}$ estão diretamente ligados à atividade microbiana obtida em cada tratamento. A 
atividade microbiana foi expressa como a quantidade de nitrogênio incorporado (Ni) na massa microbiana. Para a obtenção da quantidade de $\mathrm{N}_{i}$ foi utilizada a relação entre fósforo e nitrogênio (Van Nevel \& Demeyer, 1977) nos diferentes componentes celulares:

$$
N_{i}=P_{i} \times 8,37
$$

$O$ resultado de $N_{i}$ dos tubos não paralisado antes da incubação foi subtraído do resultado de $\mathrm{Ni}$ do tubo paralisado, calculando-se o valor de $\mathrm{N}_{\mathrm{i}}$ final.

\subsubsection{Produção de gases in vitro}

Foram feitos dois ensaios com três réplicas de cada amostra. As amostras foram colocadas em garrafas de vidro de $160 \mathrm{ml}$, previamente identificadas e nestas, foi colocado cerca de $1 \mathrm{~g}$ de amostra. Também foram preparadas 3 garrafas sem substrato, usadas como branco. Réplicas das amostras foram incubadas, em idênticas condições, com a adição de PVPP. A cada garrafa foram adicionados $90 \mathrm{ml}$ de uma solução nutritiva (item 4.4.2.1). As garrafas foram fechadas com rolhas de borracha, lacradas com anel de alumínio e levadas à incubadora a $39^{\circ} \mathrm{C}$. Preparou-se o inóculo (item 4.4.2.2), e imediatamente após, introduziram-se $10 \mathrm{ml}$ em cada garrafa, através do uso de seringa e agulha de médio calibre $(25 \times 8)$. As amostras foram homogeneizadas e em seguida, retornadas à incubadora. Este foi considerado o tempo zero. $\mathrm{O}$ período de incubação foi de 96 horas. 


\subsubsection{Solução nutritiva}

Como meio de cultura, utilizou-se uma solução nutritiva preparada para fornecer minerais aos microrganismos e uma solução com poder tamponante para que não fosse inibido o crescimento microbiano pela não renovação do meio.

A solução mineral compreendeu uma solução de macrominerais:

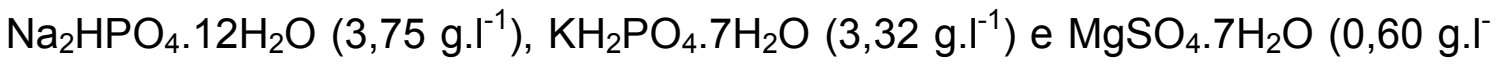

$1)$; uma solução de microminerais: $\mathrm{CaCl}_{2} \cdot 2 \mathrm{H}_{2} \mathrm{O}\left(132,00{\mathrm{~g} . l^{-1}}^{-1}, \mathrm{MnCl}_{2} \cdot 4 \mathrm{H}_{2} \mathrm{O}\right.$

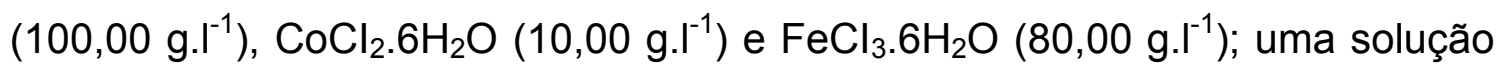
tamponante com $\mathrm{NH}_{4} \mathrm{HCO}_{3}\left(4,00 \mathrm{g.l}^{-1}\right)$ e $\mathrm{NaHCO}_{3}\left(35,00 \mathrm{g.l}^{-1}\right)$; um meio B com

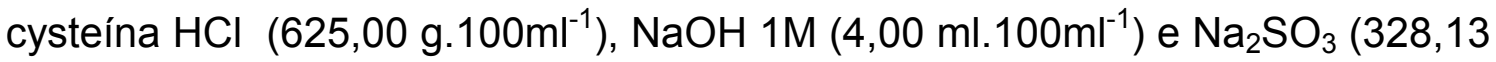

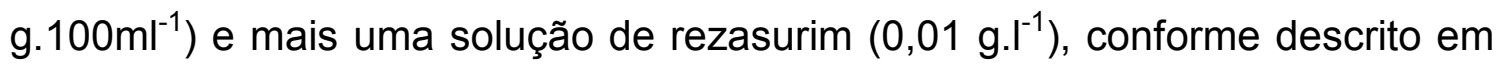
Theodorou et al. (1994). As soluções de macrominerais, microminerais, tampão, meio $B$ e rezasurim foram preparadas com antecedência de um dia para a incubação. Todas as soluções foram misturadas no início do experimento, para o preparo da solução nutritiva final, que foi feita com borbulhamento constante de dióxido de carbono.

\subsubsection{Inóculo}

O líquido do rúmen foi coletado antes da alimentação matinal dos animais, via fístula de rúmen, através de uma sonda e a porção sólida coletada com o uso de uma pinça. Ambos materiais foram colocados em garrafas térmicas pré-lavadas e aquecidas a $39^{\circ} \mathrm{C}$.

O líquido do rúmen coletado foi misturado com a fração sólida na mesma proporção (50 \% de material da fase sólida e $50 \%$ da fase líquida) e homogeneizado em um liquidificador por 10 segundos. Isto foi necessário para 
a recuperação dos microrganismos celulolíticos que se aderem fortemente à fração sólida. O material foi filtrado com o auxílio de um saco de nylon. As frações filtradas foram misturadas e mantidas em banho-maria a $39^{\circ} \mathrm{C}$, com dióxido de carbono insuflado sobre a solução continuamente.

\subsubsection{Incubação e medidas de pressão}

As garrafas foram mantidas em incubação a $39^{\circ} \mathrm{C}$, por 96 horas, sendo retiradas da incubadora apenas para as leituras. Após 96 horas de incubação, as garrafas foram colocadas em água com gelo para cessar a atividade microbiana.

Os gases produzidos durante os diferentes períodos da fermentação $(3,6,9,12,16,24,36,48,60,72$ e 96 horas) foram medidos com um transducer - medidor de pressão (Theodororou et al., 1994, Bueno, 1998).

De cada leitura de pressão, foi subtraído o total produzido pelas garrafas sem substrato (branco) referente a cada amostra.

Os resultados foram obtidos através do modelo de France et al. (1993).

\subsubsection{Digestibilidade in vitro da matéria seca}

Após as 96 horas de incubação, as garrafas foram abertas e o seu conteúdo, filtrado em cadinhos de vidro com placas de porcelana porosa de peso previamente conhecido. Os cadinhos foram colocados em estufa a $100^{\circ} \mathrm{C}$, por 48 horas e pesados. A diferença entre pesos forneceu a quantidade de MS do resíduo. Subtraindo-se da MS residual do branco, obteve-se a MS residual do substrato analisado. A relação entre a quantidade de MS residual e de MS 
inicial forneceu a porcentagem de MS não digerida. Por diferença, obteve-se a MS digerível.

A digestibilidade in vitro da MS digerível $\left(\mathrm{g} \cdot \mathrm{kg}^{-1} \mathrm{MS}\right)$ foi dada pela fórmula:

$$
\text { Deg=1000x(1-(resíduo-branco))/peso seco }
$$

\subsubsection{Cálculo da produção de gases}

Sengudo Maurício et al. (1998), existe uma forte correlação entre volume e pressão, e essa relação é expressa por: $v=0,18+3,67 p+p^{2}$; onde $v$ é o volume produzido de gases e p é a pressão (em psi).

Com o uso dessa equação, foi feita a transformação dos dados obtidos das leituras em pressão (em psi), para volume de gases produzidos.

\subsubsection{Degradabilidade ruminal in situ}

Os animais usados para medir a degradabilidade foram mantidos em uma dieta básica, composta de $80 \%$ de volumoso (feno de braquiária), $20 \%$ de concentrado comercial (FRI-OVINOS) e sal mineral (FRI-PHOS OVINOS).

Aproximadamente $3 \mathrm{~g}$ de substrato, seco e moído a $2 \mathrm{~mm}$, foram colocados em sacolinhas de nylon (9x16 cm com poros de $50 \mu \mathrm{m})$, com peso previamente conhecido, com três repetições para cada alimento. Cada repetição foi incubada no rúmen de um animal diferente. Foram feitas sacolinhas para os seguintes períodos de incubação: 4, 8, 16, 24, 48, 72 e 96 
horas, e mais duas sacolinhas para se determinar a perda por lavagem e outras duas para a determinação de matéria seca (MS).

No final de cada tempo de incubação, uma sacolinha de cada animal era retirada do rúmen e imediatamente mergulhada em água com gelo, para cessar a atividade microbiana. Após lavagem em água corrente, para a retirada das impurezas externas, as sacolinhas foram congeladas. No final do período de incubação (96 h), as sacolinhas foram lavadas por 30 minutos em uma lavadora automática. Também foram lavadas no mesmo processo, sacolinhas com os substratos, porém, sem terem passado por nenhum processo de incubação. Todas as sacolinhas foram secas em estufa $\left(60^{\circ} \mathrm{C}\right)$ até peso constante e, então, pesadas novamente.

Os resultados dos pesos foram processados em um software desenvolvido para o modelo de Ørskov e McDonald (1979), modificado por McDonald (1981), dado pela equação exponencial $p=a+b\left(1-e^{-c \dagger}\right)$. Neste modelo, $p$ representa a degradação da MS no tempo $t,(a+b)$ a degradabilidade potencial, c é a taxa de degradação, e $a, b$ e c são constantes da equação exponencial. O programa fornece ainda como resultados o "lag time", a solubilidade em água $(A)$ e as quantidades de material insolúvel, porém fermentável, definido como $B=(a+b)-A$, além de estimativa da degradabilidade efetiva do material, considerando as taxas de passagens de 2,5 e $8 \% \cdot h^{-1}$.

\subsection{Análise estatística}

Os resultados da composição bromatológica, compostos fenólicos e síntese microbiana in vitro foram obtidos a partir de duas réplicas e estes ensaios foram conduzidos com uma amostra-controle para se obter precisão na 
análise. Resultados da mesma amostra, com desvio superior a $10 \%$, foram descartados e as análises refeitas.

Os resultados do ensaio in situ foram obtidos de modo semelhante e os dados foram correlacionados com os teores de fenóis (SAS, 2000).

Os resultados dos ensaios in vitro de produção de gases foram submetidos à análise de variância e as médias foram comparadas pelos quadrados mínimos (SAS, 2000). 


\section{RESULTADOS E DISCUSSÃO}

\subsection{Análise químicas}

Os resultados da análise bromatológica das plantas estudadas são apresentados na Tabela 3.

Tabela 3. Análise bromatológica das plantas estudadas

\begin{tabular}{lccccccc}
\hline \multicolumn{1}{c}{ Amostra } & MS & MM $^{*}$ & $\mathrm{EE}^{*}$ & $\mathrm{FDN}^{*}$ & $\mathrm{FDA}^{*}$ & LDA $^{*}$ & $\mathrm{~PB}^{*}$ \\
\hline Alfafa & 427,2 & 79,7 & 38,0 & 372,2 & 295,1 & 58,5 & 204,5 \\
Angico & 545,2 & 43,1 & 60,5 & 404,3 & 295,3 & 113.1 & 162,0 \\
Aroeira & 420,8 & 51,6 & 56,2 & 416,5 & 233,5 & 98,0 & 130,6 \\
Feijão bravo & 570,7 & 80,0 & 66,1 & 497,6 & 352,3 & 134,0 & 117,1 \\
Feijão guandu & 238,7 & 46,1 & 26,7 & 639,2 & 500,9 & 127,9 & 138,1 \\
Feno de leucena & 888,7 & 60,6 & 26,6 & 629,9 & 424,8 & 250,5 & 186,8 \\
Gliricídia & 219,2 & 49,7 & 42,6 & 407,5 & 318,6 & 220,3 & 213,7 \\
Jurema preta & 424,2 & 39,1 & 81,2 & 462,6 & 325,1 & 145,3 & 159,6 \\
Leucena & 295,4 & 62,3 & 53,4 & 326,2 & 218,9 & 76,7 & 175,9 \\
Malva branca & 377,9 & 53,6 & 26,3 & 513,7 & 358,1 & 74,1 & 134,6 \\
Mela-bode & 372,5 & 67,7 & 26,7 & 485,8 & 346,9 & 91,4 & 130,2 \\
Moleque duro & 451,9 & 78,5 & 33,5 & 538,4 & 428,9 & 129,6 & 129,5 \\
Sesbânia & 277,8 & 38,3 & 30,5 & 570,2 & 385,3 & 206,6 & 187,4 \\
\hline
\end{tabular}

* Valores expressos em g.kgMs ${ }^{-1}$. 
Todas as plantas analisadas apresentaram altos valores de proteína bruta (PB).

Embora o presente trabalho tenha sido realizado com as mesmas condições climáticas, ou seja, no período das águas, o teor em PB para alfafa foi inferior aos indicados por Sales et al., 2001 (223,00 g/kg MS). Esses mesmos autores obtiveram para fibra em detergente ácido (FDA) e lignina (LDA) da alfafa os resultados de 292,80 e 57,7 g/kg MS respectivamente, dados estes, muito próximos dos obtidos. Já para fibra em detergente neutro (FDN), o resultado do presente experimento foi inferior ao observado na literatura (502,40 g/kg MS) (Sales et al., 2001).

Para o feijão bravo, os valores de PB e extrato etéreo (EE) estão abaixo dos valores citados por Araújo et al. (1996) em feno de feijão bravo que foi de 134,70 e $83,10 \mathrm{~g} / \mathrm{kg} \mathrm{MS}$ para PB e EE, respectivamente.

Para a jurema preta, os dados obtidos para PB (159,60 g/kg MS) e FDN (462,60 g/kg MS) diferiram dos dados da literatura (PB 197,00; FDN $532,40 \mathrm{~g} / \mathrm{kg} \mathrm{MS}$ ) de acordo com Carvalho et al., 2001. Também para PB e EE, os teores apresentaram-se menores do que os encontrados por Lima et al. (1987) para moleque-duro, malva e leguminosa.

Para leucena e gliricídia, os teores encontrados por Balogun et al. (1998) foram: 176,30 e 176,30 em PB; 335,30 e 350,80 em FDN; 236,40 e 259,70 em FDA e 84,50 e 74,50 para LDA ( $/ \mathrm{kg}$ MS), respectivamente. Os valores analisados no experimento foram semelhantes para a leucena, mas não para a gliricídia.

Em resumo, a maior parte dos dados observados no presente experimento, com relação ao teor em PB, apresentou valores menores que os valores observados na literatura.

$\mathrm{Na}$ Tabela 4, pode-se observar que plantas como o angico, aroeira e jurema preta contém altos teores de tanino e fenóis (mais de 100,00 g/kg MS de 
tanino). De acordo com a literatura, níveis de taninos na faixa de $50,00 \mathrm{~g} / \mathrm{kg} \mathrm{MS}$ são tóxicos para os animais e níveis acima de $90,00 \mathrm{~g} / \mathrm{kg}$ podem levá-los à morte. Considerando-se esses níveis, pode-se inferir dos resultados das análises na Tabela 4, que as plantas angico, aroeira, jurema preta, leucena e malva branca podem ser nocivas aos animais.

Tabela 4. Resultados das análises dos teores de compostos fenólicos

\begin{tabular}{lccc}
\hline \multicolumn{1}{c}{ Amostra } & Fenóis* $^{*}$ & Taninos* & $\begin{array}{c}\text { Taninos } \\
\text { condensados }^{*}\end{array}$ \\
\hline Alfafa & 12,51 & 7,92 & 0,30 \\
Angico & 138,45 & 126,39 & 9,00 \\
Aroeira & 204,15 & 194,19 & 43,50 \\
Feijão bravo & 26,02 & 25,26 & 1,40 \\
Feijão guandu & 27,70 & 20,34 & 6,20 \\
Feno de leucena & 30,38 & 24,30 & 10,00 \\
Gliricídia & 13,72 & 6,86 & 0,30 \\
Jurema preta & 140,06 & 122,50 & 69,20 \\
Leucena & 92,85 & 79,33 & 65,40 \\
Malva branca & 74,60 & 59,55 & 97,20 \\
Mela-bode & 21,69 & 16,11 & 0,30 \\
Moleque duro & 46,53 & 39,16 & 0,20 \\
Sesbânia & 14,35 & 10,60 & 1,90 \\
\hline
\end{tabular}

${ }^{*}$ valores expressos em g.kgMS ${ }^{-1}$.

Foi observada alta mortalidade em ovinos e bezerros alimentados com folhas de carvalhos e outras espécies contendo mais de $20 \%$ de taninos hidrolisáveis $(\mathrm{TH})$. As principais causas foram lesões gastrintestinais, hemorragias, necrose no fígado e danos nos rins (Cannas, 1999). 
Os resultados encontrados por Jones et al. (2000) para os teores de TC foram próximos de zero para gliricídia e em torno de $55 \mathrm{~g} / \mathrm{kg}$ MS para a leucena. Balogun et al. (1998) obteve valores de taninos condensados (TC) de $57 \mathrm{~g} / \mathrm{kg}$ MS para a leucena e $8,9 \mathrm{~g} / \mathrm{kg}$ MS para a gliricídia. O valor obtido no presente estudo para a leucena foi de $65,40 \mathrm{~g} / \mathrm{kg} \mathrm{MS}$, sendo maior do que descrito na literatura; para a gliricídia $(0,30 \mathrm{~g} / \mathrm{kg} \mathrm{MS})$ o teor foi semelhante ao obtido por Jones et al. (2000), e menor do que o descrito por Balogun et al. (1998).

Para as outras plantas provenientes da caatinga não foram encontrados dados na literatura.

\subsection{Síntese microbiana}

Os resultados (Tabela 5) indicaram que o uso de PVPP não foi adequado para o estudo do efeito dos fenóis e taninos totais para o método acima utilizado.

Os tubos correspondentes aos brancos com PVPP (tubos em que a atividade microbiana foi paralisada) apresentaram maior valor de atividade específica que os tubos correspondentes às amostras não paralisadas. Portanto, quando se fez a subtração (amostra - branco), alguns resultados foram incoerentes. Isto provavelmente ocorreu porque $0{ }^{32} \mathrm{P}$ extracelular pode ter ficado aderido ao PVPP, e mesmo com as lavagens, não foi possível sua remoção. 
Tabela 5. Síntese microbiana estimada a partir da incorporação de ${ }^{32} \mathrm{P}$ (em $\mathrm{mg}$ $N$ incorporado por g de MS incubada)

\begin{tabular}{lcc}
\hline \multicolumn{1}{c}{ Alimento } & com PVPP & sem PVPP \\
\hline Alfafa & 6,13 & 8,92 \\
Angico & $-1,97$ & 1,40 \\
Aroeira & 2,06 & 0,57 \\
Feijão bravo & 4,11 & 5,09 \\
Feijão guandu & 8,79 & 3,37 \\
Feno leucena & 0,25 & 6,22 \\
Gliricídia & 6,29 & 4,18 \\
Jurema preta & 2,51 & 6,45 \\
Leucena & 3,90 & 3,02 \\
Malva branca & $-0,94$ & $-0,57$ \\
Mela-bode & 5,56 & 8,02 \\
Moleque duro & 1,86 & 3,16 \\
Sesbânia & 2,08 & 4,97 \\
\hline
\end{tabular}

\subsection{Produção de gases in vitro}

O "lag time" (LAG) estima o tempo em que o alimento leva para ser colonizado, portanto, quanto menor o "lag time", mais rápido o alimento será degradado pelos microrganismos.

Pela Tabela 6, observa-se que os valores de "lag time" (tempo de colonização), para a maioria das plantas avaliadas, não apresentaram diferenças significativas $(P>0,05)$ entre os tratamentos sem e com PVPP. $O$ angico e a malva branca apresentaram diferença significativa entre os tratamentos $(P<0,01$ e $P<0,05$, respectivamente). $O$ angico teve um tempo de colonização maior pelos microrganismos na presença do PVPP $(1,865 \mathrm{~h})$ do que na ausência de PVPP $(0,935$ h), já para a malva branca, o tempo de colonização foi menor na presença do PVPP.

Para algumas plantas (angico, jurema preta e moleque duro), verificouse que a produção potencial de gases $(P O T)$ foi maior que $(P<0,05)$ na 
presença de PVPP, indicando que este composto foi efetivo em diminuir os efeitos dos taninos totais ou dos taninos condensados. Para as demais plantas, não se verificou efeito ou diminuição do POT. 
Tabela 6. Resultado da média da produção de gases sem e com PVPP para lag time (horas), potencial (ml. $\left.\mathrm{g}^{-1} \mathrm{MS}\right) \mathrm{e}$ degradabilidade (g.kg $\left.\mathrm{MS}^{-1}\right)$

\begin{tabular}{|c|c|c|c|c|c|c|c|c|c|}
\hline \multirow{2}{*}{ Alimentos } & \multicolumn{3}{|c|}{ LAG } & \multicolumn{3}{|c|}{ POT } & \multicolumn{3}{|c|}{ DEG } \\
\hline & sem & com & prob. & sem & com & prob. & sem & com & prob. \\
\hline Alfafa & 1,765 & 1,830 & ns & 170,260 & 155,105 & $* *$ & 738,230 & 744,610 & ns \\
\hline Angico & 0,935 & 1,865 & $* *$ & 69,405 & 102,940 & $* *$ & 448,910 & 440,970 & ns \\
\hline Aroeira & 2,340 & 2,355 & ns & 145,300 & 132,415 & $* *$ & 526,930 & 444,220 & $* *$ \\
\hline Feijão bravo & 1,400 & 1,250 & ns & 86,525 & 91,680 & ns & 468,250 & 444,290 & ns \\
\hline Feijão guandu & 1,975 & 2,050 & ns & 143,780 & 129,105 & $* *$ & 524,425 & 548,165 & ns \\
\hline Gliricídia & 2,230 & 2,140 & ns & 166,255 & 165,755 & ns & 697,055 & 660,840 & ns \\
\hline Jurema preta & 1,800 & 2,065 & ns & 88,665 & 109,735 & $* *$ & 426,150 & 406,060 & ns \\
\hline Leucena & 2,300 & 2,210 & ns & 151,300 & 141,745 & * & 653,895 & 598,405 & $*$ \\
\hline Feno leucena & 1,380 & 1,210 & ns & 91,640 & 98,645 & ns & 472,025 & 467,955 & ns \\
\hline Malva branca & 2,450 & 1,990 & * & 122,495 & 114,725 & ns & 597,970 & 543,245 & $*$ \\
\hline Mela-bode & 2,070 & 2,120 & ns & 156,935 & 152,505 & ns & 617,495 & 596,975 & ns \\
\hline Moleque duro & 2,565 & 2,475 & ns & 105,190 & 114,520 & $*$ & 507,225 & 483,875 & ns \\
\hline Sesbânia & 2,195 & 2,285 & ns & 142,235 & 137,430 & ns & 614,065 & 564,270 & $*$ \\
\hline SED & & 0,1518 & & & 2,8202 & & & 13,0118 & \\
\hline
\end{tabular}

ns: $P>0,05 ;{ }^{*}: P<0,05 ;{ }^{* *}: P<0,01$ 
A degradabilidade (DEG) não apresentou, para a maioria das plantas testadas, diferenças significativas $(P>0,05)$ entre os tratamentos (sem e com PVPP). Para as plantas que apresentaram um resultado significativo, verificouse que houve diminuição da DEG com a adição de PVPP, o que contradiz a expectativa.

Esses resultados indicam que a metodologia de adição de PVPP não foi satisfatória para os parâmetros LAG, POT e DEG testados.

No presente experimento, a proporção de PVPP em relação ao substrato foi de 1:1. Pela literatura, a proporção PVPP/substrato ou PVPP/nível de tanino requerida para uma ótima resposta não é clara. Khazaal \& Ørskov (1994) descreveram que a proporção de $1: 1$ foi a que resultou em melhor resposta, comparada com outras proporções (2:1 a 10:1). A baixa produção de gases ou falta de resposta observada no presente estudo pode ser parcialmente devida à quantidade insuficiente de PVPP utilizada.

Deve-se também levar em consideração que a estrutura e a composição dos fenóis e taninos totais poderiam ter influenciado nas respostas observadas.

Pela Figura 3, verifica-se que a produção de gases durante todo o período de incubação só apresentou um aumento, com a adição de PVPP, para as plantas angico e jurema preta (a partir de $24 \mathrm{~h}$ de incubação). Na Tabela 7 , observa-se que, para os períodos de 48 e 96 horas, os valores da produção de gases só foram significativos para essas duas plantas.

As respostas observadas podem estar ligadas à estrutura molecular dos taninos presentes em cada espécie estudada.

É importante ressaltar que não existem na literatura estudos deste tipo com a maioria dessas espécies de plantas. 

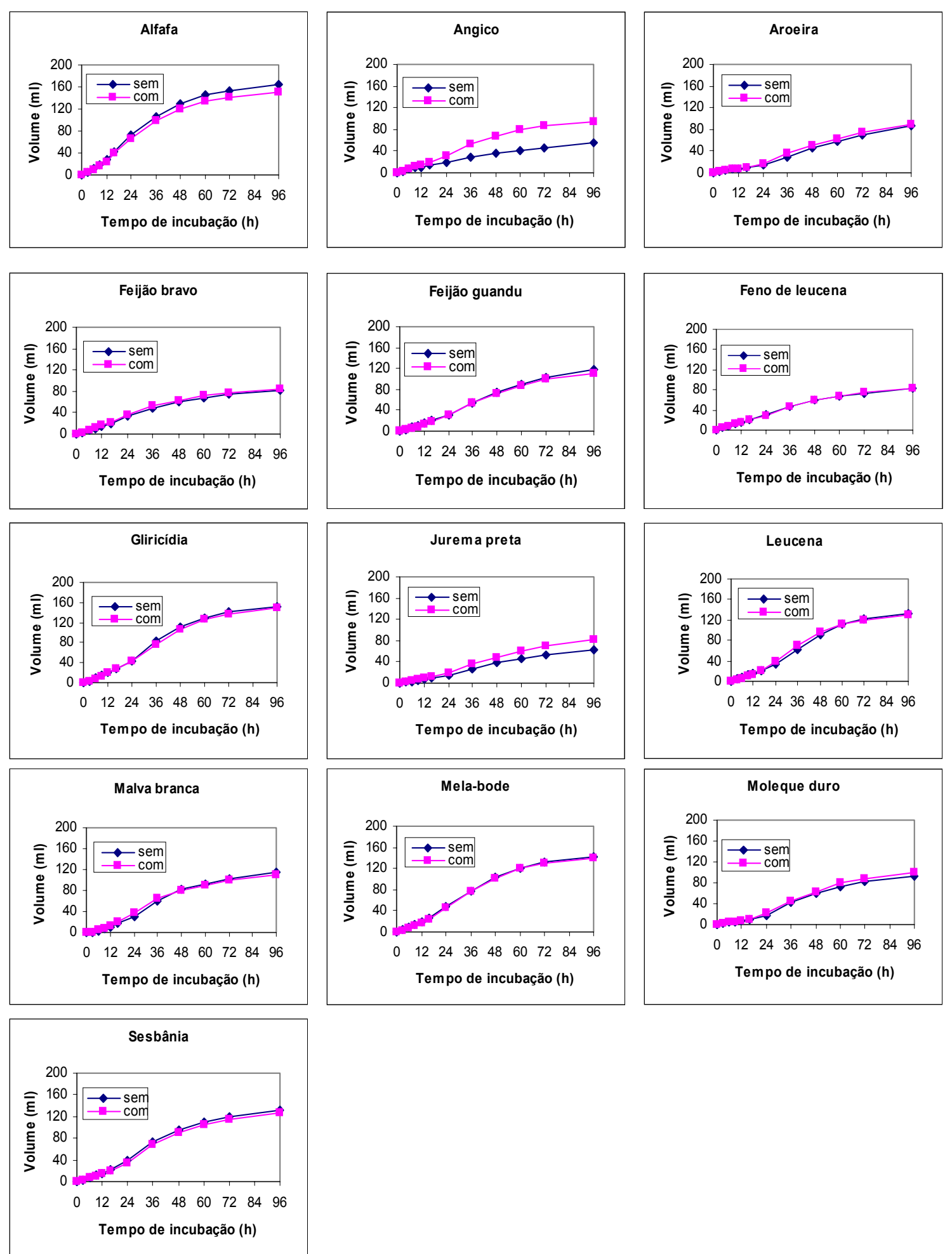

Figura 3. Curvas de produção acumulada de gases (em $\mathrm{ml} \cdot \mathrm{g}^{-1} \mathrm{MS}$ ) evidenciando a cinética do processo fermentativo sem e com PVPP 
Tabela 7. Resultado da média da produção de gases sem e com PVPP para G48 e G96 horas

\begin{tabular}{lcccccc}
\hline \multirow{2}{*}{ Alimentos } & \multicolumn{7}{c}{ G48 } & & & G96 & \\
\cline { 2 - 7 } & sem & com & prob. & sem & com & prob. \\
\hline Alfafa & 128,700 & 120,360 & $\mathrm{~ns}$ & 164,130 & 151,680 & $*$ \\
Angico & 36,530 & 67,920 & $* *$ & 54,760 & 93,615 & $* *$ \\
Aroeira & 45,640 & 50,290 & $\mathrm{~ns}$ & 86,055 & 89,420 & $\mathrm{~ns}$ \\
Feijão bravo & 59,975 & 62,385 & $\mathrm{~ns}$ & 80,730 & 84,820 & $\mathrm{~ns}$ \\
Feijão guandu & 73,165 & 73,025 & $\mathrm{~ns}$ & 116,760 & 111,445 & $\mathrm{~ns}$ \\
Gliricídia & 112,025 & 107,260 & $\mathrm{~ns}$ & 151,940 & 148,390 & $\mathrm{~ns}$ \\
Jurema preta & 37,740 & 49,055 & $*$ & 63,375 & 82,805 & $*$ \\
Leucena & 91,360 & 95,630 & $\mathrm{~ns}$ & 132,435 & 130,635 & $\mathrm{~ns}$ \\
Feno leucena & 58,920 & 58,625 & $\mathrm{~ns}$ & 82,175 & 83,715 & $\mathrm{~ns}$ \\
Malva branca & 81,370 & 80,820 & $\mathrm{~ns}$ & 115,085 & 109,160 & $\mathrm{~ns}$ \\
Mela-bode & 102,415 & 101,110 & $\mathrm{~ns}$ & 142,465 & 138,650 & $\mathrm{~ns}$ \\
Moleque duro & 59,695 & 63,375 & $\mathrm{~ns}$ & 91,490 & 99,045 & $\mathrm{~ns}$ \\
Sesbânia & 95,855 & 90,615 & $\mathrm{~ns}$ & 132,625 & 127,310 & $\mathrm{~ns}$ \\
\hline SED & \multicolumn{7}{c}{2,0463} & & 2,9638 & \\
\hline
\end{tabular}

ns: $P>0,05 ;{ }^{*}: P<0,05 ;{ }^{* *}: P<0,01$

A Tabela 8 demonstra os resultados das relações REL1 e REL2. Quanto à REL1, pode-se observar que para a maioria das plantas avaliadas não se verificou diferença significativa $(P>0,05)$ entre os tratamentos. Apenas 0 angico e a leucena apresentaram diferença significativa $(P<0,01$ e $P<0,05$, respectivamente).

A REL2 demonstrou que, para a grande maioria dos alimentos, o tempo do ensaio foi suficiente para expressar o potencial de produção de gases, o que possibilitou um bom ajuste dos dados pelo modelo matemático. $\mathrm{A}$ adição de PVPP melhorou a REL2 para angico e aroeira. Isto significa que a taxa de fermentação atingiu valores próximos ao seu potencial máximo em 96 horas. 
Tabela 8. Resultado da média da produção de gases sem e com PVPP para Relação 1 e Relação 2

\begin{tabular}{|c|c|c|c|c|c|c|}
\hline \multirow{2}{*}{ Alimentos } & \multicolumn{3}{|c|}{ Rel.1 } & \multicolumn{3}{|c|}{ Rel.2 } \\
\hline & sem & com & prob. & sem & com & prob. \\
\hline Alfafa & 0,785 & 0,795 & ns & 0,965 & 0,980 & ns \\
\hline Angico & 0,670 & 0,725 & $* *$ & 0,790 & 0,910 & $* *$ \\
\hline Aroeira & 0,530 & 0,565 & ns & 0,615 & 0,705 & $* *$ \\
\hline Feijão bravo & 0,745 & 0,735 & ns & 0,935 & 0,925 & ns \\
\hline Feijão guandu & 0,625 & 0,655 & ns & 0,810 & 0,860 & ns \\
\hline Gliricídia & 0,735 & 0,725 & ns & 0,915 & 0,895 & ns \\
\hline Jurema preta & 0,595 & 0,595 & ns & 0,720 & 0,755 & ns \\
\hline Leucena & 0,690 & 0,735 & * & 0,875 & 0,925 & ns \\
\hline Feno leucena & 0,715 & 0,705 & ns & 0,895 & 0,850 & ns \\
\hline Malva branca & 0,705 & 0,740 & ns & 0,940 & 0,950 & ns \\
\hline Mela-bode & 0,720 & 0,730 & ns & 0,910 & 0,915 & ns \\
\hline Moleque duro & 0,650 & 0,640 & ns & 0,865 & 0,870 & ns \\
\hline Sesbânia & 0,720 & 0,715 & ns & 0,930 & 0,925 & ns \\
\hline SED & & 0,0117 & & & 0,0171 & \\
\hline
\end{tabular}

ns: $\mathrm{P}>0,05 ;{ }^{*}: \mathrm{P}<0,05 ;{ }^{* *}: \mathrm{P}<0,01$

A Tabela 9 ilustras as correlações entre compostos fenólicos e parâmetros de produção de gases. Houve correlação negativa $(P<0,01)$ entre produção de gases e fenóis e taninos totais para 48 e 96 horas, significando que quanto maior a quantidade desses fatores antinutricionais, menor será a produção de gases.

Em relação à metodologia de produção de gases, o parâmetro que melhor refletiu o efeito dos fatores antinutricional dos fenóis e taninos totais foi a quantidade de gases produzida. 
Tabela 9. Correlações entre compostos fenólicos e parâmetros de produção de gases

\begin{tabular}{lccccc}
\hline \multicolumn{1}{c}{ Variáveis } & LAG & $P O T$ & $D E G$ & $G 48$ & G96 \\
\hline Fenóis totais & 0,097 & $-0,262$ & $-0,498$ & $-0,626$ & $-0,551$ \\
& $\mathrm{~ns}$ & $\mathrm{~ns}$ & $* *$ & $* *$ & $* *$ \\
Taninos totais & 0,084 & $-0,262$ & $-0,505$ & $-0,632$ & $-0,557$ \\
& $\mathrm{~ns}$ & $\mathrm{~ns}$ & $* *$ & $* *$ & $* *$ \\
Taninos condensados & 0,234 & $-0,109$ & $-0,149$ & $-0,237$ & $-0,200$ \\
& $\mathrm{~ns}$ & $\mathrm{~ns}$ & $\mathrm{~ns}$ & $\mathrm{~ns}$ & $\mathrm{~ns}$ \\
\hline
\end{tabular}

ns: $P>0,05 ;{ }^{*}: P<0,05 ; * *: P<0,01$

\subsection{Degradabilidade ruminal in situ}

Os parâmetros de degradabilidade encontram-se na Tabela 10, e a Tabela 11 indica as correlações entre esses parâmetros e os teores de fenóis.

As taxas de degradabilidade (c) para as plantas angico, aroeira e jurema preta foram menores que para as demais. Esses resultados, comparados com os anteriores, para a produção de gases, parecem indicar que as plantas angico, aroeira e jurema preta foram as mais efetivas em produzirem efeitos adversos. Confirmando esses achados, a relação entre a degradabilidade efetiva a $2 \%$ com a degradabilidade potencial (Tabela 10) foram baixas para essas três plantas.

Quanto mais essa relação tende a 1 (Tabela 10), maior é o valor nutricional da planta, portanto, o angico, a aroeira e a jurema preta foram as plantas que apresentaram menor valor nutritivo.

As correlações entre FT, TT e TC e a taxa de degradabilidade (Tabela 11) foram negativas. Isto mostra que esses compostos afetaram adversamente a degradabilidade. Deve-se lembrar que vários fatores podem influenciar a degradabilidade, como os teores em fibra e lignina. Somente com os resultados 
observados não se pode concluir que a metodologia in situ demonstrou realmente o efeito adverso dos fenóis.

Tabela 10. Média das constantes (c) do modelo $p=a+b\left(1-e^{-c t}\right)$ de degradabilidade, das frações prontamente solúveis (A) e não solúveis fermentáveis (B), das degradabilidades potenciais (Pot) e efetivas a uma taxa de passagem de $2 \% \cdot h^{-1}$ (Ef2), dos substratos testados

\begin{tabular}{lcccccc}
\hline \multicolumn{1}{c}{ Alimento } & $\mathrm{C}$ & $\mathrm{A}^{1}$ & $\mathrm{~B}^{1}$ & Pot $^{1}$ & ${\text { Ef } 2^{1}}$ & Relação $^{2}$ \\
\hline Alfafa & $0,185 \pm 0,068$ & $32,28 \pm 0,00$ & $44,81 \pm 0,46$ & $77,09 \pm 0,46$ & $70,24 \pm 0,83$ & 0,91 \\
Angico & $0,019 \pm 0,009$ & $17,65 \pm 0,00$ & $19,41 \pm 2,40$ & $37,06 \pm 2,40$ & $25,57 \pm 1,49$ & 0,69 \\
Aroeira & $0,016 \pm 0,006$ & $21,99 \pm 0,00$ & $67,38 \pm 7,76$ & $89,37 \pm 7,76$ & $49,48 \pm 2,42$ & 0,55 \\
Feijão bravo & $0,109 \pm 0,039$ & $31,38 \pm 0,00$ & $27,51 \pm 0,95$ & $58,89 \pm 0,95$ & $53,06 \pm 1,89$ & 0,90 \\
Feijão guandu & $0,055 \pm 0,012$ & $23,95 \pm 0,00$ & $34,09 \pm 1,21$ & $58,04 \pm 1,21$ & $47,63 \pm 1,44$ & 0,82 \\
Feno de leucena & $0,032 \pm 0,001$ & $17,38 \pm 0,00$ & $27,91 \pm 1,72$ & $45,29 \pm 1,72$ & $34,41 \pm 1,12$ & 0,76 \\
Gliricídia & $0,054 \pm 0,012$ & $31,43 \pm 0,00$ & $40,89 \pm 3,77$ & $72,32 \pm 3,77$ & $60,42 \pm 0,53$ & 0,84 \\
Jurema preta & $0,023 \pm 0,009$ & $25,21 \pm 0,00$ & $52,34 \pm 5,79$ & $77,55 \pm 5,79$ & $50,27 \pm 3,20$ & 0,65 \\
Leucena & $0,063 \pm 0,022$ & $39,07 \pm 0,00$ & $40,06 \pm 1,14$ & $79,13 \pm 1,14$ & $66,96 \pm 0,58$ & 0,85 \\
Malva branca & $0,048 \pm 0,012$ & $26,07 \pm 0,00$ & $42,33 \pm 1,50$ & $68,40 \pm 1,50$ & $54,66 \pm 2,29$ & 0,80 \\
Mela-bode & $0,120 \pm 0,073$ & $34,81 \pm 0,00$ & $32,58 \pm 0,17$ & $67,39 \pm 0,17$ & $59,89 \pm 3,19$ & 0,89 \\
Moleque duro & $0,064 \pm 0,016$ & $23,79 \pm 0,00$ & $37,92 \pm 2,09$ & $61,71 \pm 2,09$ & $50,57 \pm 0,10$ & 0,82 \\
Sesbânia & $0,180 \pm 0,043$ & $19,03 \pm 0,00$ & $54,43 \pm 0,60$ & $73,46 \pm 0,60$ & $64,38 \pm 0,91$ & 0,88 \\
\hline
\end{tabular}

${ }^{1} \mathrm{em} \%$.

${ }^{2}$ Relação $=$ Ef2/Pot 
Tabela 11. Correlações entre compostos fenólicos e parâmetros de degradabilidade ruminal

\begin{tabular}{lccccc}
\hline \multicolumn{1}{c}{ Variáveis } & $c$ & $A$ & $B$ & Pot & Ef2\% \\
\hline \multirow{2}{*}{ Fenóis totais } & -0.6083 & -0.2665 & 0.3827 & 0.2292 & -0.3926 \\
& $* *$ & $\mathrm{~ns}$ & $*$ & $\mathrm{~ns}$ & $*$ \\
Taninos totais & -0.5923 & -0.2740 & 0.2290 & 0.2290 & -0.3949 \\
& $* *$ & $\mathrm{~ns}$ & $\mathrm{~ns}$ & $\mathrm{~ns}$ & $*$ \\
Taninos condensados & -0.4141 & 0.0949 & 0.3725 & 0.3725 & 0.5001 \\
& $*$ & $\mathrm{~ns}$ & $*$ & $*$ & $\mathrm{~ns}$ \\
\hline
\end{tabular}

ns: $P>0,05 ;{ }^{*}: P<0,05 ;{ }^{* *}: P<0,01$ 


\section{CONCLUSÕES}

> Com os métodos utilizados, foi possível identificar plantas que podem ser tóxicas aos animais;

- Os métodos químicos para a determinação de fenóis totais, taninos totais e taninos condensados; a medida da produção de gases e a técnica de degradabilidade in situ foram satisfatórias para selecionar plantas taniníferas que possuem potencial como alimento aos ruminantes;

$>$ O uso do PVPP não foi adequado para minimizar o efeito adverso dos fenóis em técnicas in vitro.

Sugere-se que:

a) $O$ polietileno glicol (PEG), seja utilizado em experimento in vitro e comparado ao PVPP em relação à capacidade de diminuir ou cancelar o efeito dos fenóis presentes nas plantas;

b) Experimentos in vivo devam ser feitos, em adição à técnicas in vitro e in situ, para verificar o efeito das plantas taniníferas no consumo, digestibilidade e metabolismo de nitrogênio. 


\section{REFERÊNCIAS BIBLIOGRÁFICAS}

AERTS, R.J.; BARRY, T.N.; McNABB, W.C. Polyphenols and agriculture: beneficial effects of proanthocyanidins in forages. Agriculture, Ecosystems and Environment, v.75, p.1-12, 1999.

AGRICULTURAL AND FOOD RESEARCH COUNCIL - AFRC. Energy and protein requirement of ruminants. Wallingford: $C A B$ International, 1993. $159 p$.

ARAÚJO FILHO, J.A.; SILVA, N.L.; SOUSA, F.B.; CARVALHO, F.C.; SENA, F.C.F. Fenologia, produção e valor nutritivo de espécies lenhosas da caatinga. In: REUNIÃO ANUAL DA SOCIEDADE BRASILEIRA DE ZOOTECNIA, 33., Fortaleza, 1996. Anais. Fortaleza: UFV, 1996. p.18-22.

ASSOCIATION OF OFFICIAL AGRICULTURAL CHEMISTS. Official methods of analysis of the AOAC. 16.ed. Arlington: AOAC International, 1995. v.1, p.4/1-4/30.

BALOGUN, R.O.; JONES, R.J.; HOLMES, J.H.G. Digestibility of some tropical browse species varying in tannin content. Animal Feed Science and Technology, v.76, p.77-88, 1998.

BEEVER, D.E.; HARRISON, D.G.; THOMPSON, D.J.; CAMMELL, S.B.; OSBOURN, D.F. A method for the estimation of dietary and microbial protein in duodenal digesta of ruminants. British Journal of Nutrition, v.32, p.99-112, 1974. 
BOUGHDAD, A.; GILLON, Y.; GAGNEPAIN, C. Effect of the ripe seed husks of vicia-faba on the larval development of callosobruchus-maculatus. Entomologia Experimentalis et Applicata, v.42, n.3, p.219-223, 1986.

BRANDES, D.; FEITAS, E.A.G. Taninos condensados - uma ferramenta para melhorar o desempenho de ruminante. Agropecuária Catarinense, v.5, n.3, p.44-48, 1992.

BUENO, I.C.S. Comparação entre técnica in vitro e in situ de avaliação de braquiária para ruminantes. Piracicaba, 1998. 133p. Dissertação (Mestrado) - Centro de Energia Nuclear na Agricultura, Universidade de São Paulo.

BUENO, I.C.S.; CABRAL FILHO, S.L.S.; GOBBO, S.P.; MACHADO, M.C.; PAVAN, C.; ABDALLA, A.L. Effect of tropical diets on inocula used on in vitro gas production technique. In: ANNUAL MEETING OF THE BRITISH SOCIETY OF ANIMAL SCIENCE, York, 2001. Proceedings. Penicuik: BSAS, 2001. p.110.

BUNN, S.E. Processing of leaf litter in 2 northern jarrah forest streams, Western-Australia.2. The role of macroinvertebrates and the influence of soluble polyphenols and inorganic sediment. Hydrobiologia, v.162, n.3, p.211-223, 1988.

BUTLER, L.G. New perspectives on the antinutritional effects of tannins. In: KINSELLA, J.E.; SOUCIE, B. (Ed.) Foods products. Champaign: American Oil Chemistry Society, 1989. cap.22, p.402-409.

BUTLER, L.G. Polyphenols and their effects on sorghum quality. In: INTERNATIONAL SYMPOSIUM ON SORGHUM GRAIN QUALITY, Palancheru, 1981. Proceedings. Palancheru: ICRISAT, 1982. p.294-311.

BUTLER, L.G.; RIEDL, D.J.; LEBRYK, D.G.; BLYTT, H.J. Interaction of proteins with sorghum tannin: mechanism, specificity and significance. Journal of American Oil Chemistry Society, v.61, n.5, p.916-920, 1984. 
CANNAS, A. Tannins: fascinating but sometimes dangerous molecules. Itaka, 1999. http://www.ansci.cornell.edu/plants/toxicagents/tannin/tannin.htm (30/03/1999).

CARVALHO, M.V.B.M.A.; FERREIRA, R.L.C.; SANTOS, M.V.F.; DUBEUX JÚNIOR, J.C.B.; FREITAS, A.M.M.; ALMEIDA, O.C. Identificação e composição bromatológica de espécies arbóreas e arbustivas ocorrentes em áreas de pastagem do agreste de Pernambuco. (Compact disc). In: REUNIÃO ANUAL DA SOCIEDADE BRASILEIRA DE ZOOTECNIA, 38., Piracicaba, 2001. Anais. Piracicaba: SBZ, 2001.

COLEY, P.D. Herbivory and defensive characteristics of tree species in a lowland tropical forest. Ecological Monographs, v.53, n.2, p.209-233, 1983.

DESCHAMPS, A.M. Evaluation of the degradation of 2 types of tannin condensed by bacteria isolated from decaying bark. Canadian Journal of Microbiology, v.31, n.5, p.499-502, 1985.

DESCHAMPS, A.M.; LEBEAULT, J.M. Production of gallic acid from tara (Caesalpinia spinosa) tannin by bacterial strains. Biotechnology Letters, v.6, p.237-242, 1985.

DESHPANDE, S.S.; CHERYAN, M.; SALUNKHE, D.K. Tannin analysis of food products. CRC Critical Reviews in Food Science and Nutrition, v.24, p.401-449, 1986.

FISKE, C.H.; SUBBAROW, Y. The calorimetric determination of phosphorus. Journal of Biological Chemistry, v.66, p.1719-1725, 1925.

FRANCE, J.; DHANOA, M.S.; THEODOROU, M.K.; LISTER, S.J.; DAVIES, S.J.; ISAC, D. A model to interpret gas accumulation profiles with in vitro degradation of ruminant feeds. Journal of Theoretical Biology, v.163, p.99-111, 1993. 
GETACHEW, G. Tannins in tropical multipurpose tree species: localization and quantification of tannins using histochemical approaches and the effect of tannins on in vitro rumen fermentation. Stuttgart: Verlag Ulrich E. Grauer, 1999. 186p.

GETACHEW, G.; BLÜMMEL, M.; MAKKAR, H.P.S.; BECKER, K. In vitro gas measuring techniques for assessment of nutritional quality of feeds: a review. Animal Feed Science and Technology, v.72, p.261-281, 1998.

GETACHEW, G.; MAKKAR, H.P.S.; BECKER K. Effect of polyethylene glycol on in vitro degradability of nitrogen and microbial protein synthesis from tannin-rich browse and herbaceous legumes. British Journal of Nutrition, v.84, p.73-83, 2000.

GOBBO, S.P.; BUENO, I.C.S.; ABDALLA, A.L.; PEÇANHA, M.R.S.R.; CABRAL FILHO, S.L.S. Técnica in vitro de incorporação de radiofósforo para estimativa de síntese microbiana: Influência do número de lavagens na remoção de radiofósforo extracelular contaminante. (Compact disc). In: REUNIÃO ANUAL DA SOCIEDADE BRASILEIRA DE ZOOTECNIA, 37., Viçosa, 2000. Anais. Viçosa: SBZ, 2000.

GREEN, F.B.; CORCORAN, M.R. Inhibitory action of 5 tannins on growth induced by several gibberellins Plant Physiology, v.56, n.6, p.801-806, 1975.

HAGERMAN, A.E.; BUTLER L.G. The specificity of proanthocyanidin-protein interactions. Journal of Biological Chemistry, v.256, p.4494-4497, 1981.

HASLAM, E. Natural polyphenols (vegetable tannins) as drugs: possible modes of action. Journal of Natural Products, v.59, p.205-215, 1996.

HASLAM, E. Plant polyphenois-vegetable tannins revisited. Cambridge: Cambridge University Press, 1989. 
HUTTON, K.; BAILEY, F.J.; ANNISON, E.F. Measurements of the bacterial nitrogen entering the duodenum of the ruminant using Diaminop Melic Acid as a marker. British Journal of Nutrition, v.25, p.165-173, 1971.

JONES, R.J.; MEYER, J.H.F.; BECAS, M.; STOLTZ, M.A. An approach to screening potential pasture species for condensed tannin activity. Animal Feed Science and Technology, v.85, p.269-277, 2000.

KATOH, T.; KASUYA, M.; KAGAMIMORI, S.; KOZUKA, H.; KAWANO, S. Effects of air-pollution on tannin biosynthesis and predation damage in cryptomeria-japonica. Phytochemistry, v.28, n.2, p.439-445, 1989.

KHAZAAL, K.; MARKANTONATOS, X.; NASTIS, A.; ØRSKOV, E.R. Changes with maturity in fibre composition and levels of extractable polyphenols in Greek browse: effects on in vitro gas production and in sacco dry matter degradation. Journal of the Science of Food and Agriculture, v.63, p.237-244, 1993.

KHAZAAL, K.; ØRSKOV, E.R. The in vitro gas production technique: an investigation on its potential use with insoluble polyvinylpolypyrrolidone for the assessment of phenolics-related anti-nutritive factors in browse species. Animal Feed Science and Technology, v.47, p.305-320, 1994.

LEINMÜLLER, H.S.; KARL-HEINZ, M. Tannins in ruminant feedstuffs. Animal Research and Development, v.33, p.9-62, 1991.

LEWIS, N.G.; YAMAMOTO, E. Tannins: their place in plant metabolism. In: HEMINGWAY, R.W.; KARCHESY, J.J. (Ed) Chemistry and significance of condensed tannins. New York: Plenum Press, 1989. p.23-46.

LIMA, M.A.; FERNANDES, A.P.M.; SILVA, M.A.; VIEIRA, M.E.Q.; SILVA, M.J.A.; SILVA, V.M.; ALVES, L.G.A. Avaliação de forragens nativas e cultivadas em áreas da caatinga no Sertão de Pernambuco. Revista da Sociedade Brasileira de Zootecnista, v.16, n.6, p.513-531, 1987. 
LOHAN, O.P.; LALL, D.; VOID, J.; NEGI, S.S. Utilization of oak tree (Quercus incana) fodder in cattle rations and fate of oak-leaf tannins in the ruminant system. Indian Journal of Animal Science, v.53, p.1057-1063, 1983.

LONGLAND, A.C.; THEODOROU, M.K.; LISTERL, S.J.; MORRIS, P.; GILL, M. The ability of polyethylene glycol to enhance the digestion of tropical forage legumes of varying tannins content. In: Annual Meeting of the British Society of Animal Science, 45., Edinburgh. 1994. Proceedings. Penicuik: BSAS, 1994.

MAKKAR, H.P.S. Quantification of tannins in tree foliage. Vienna: FAO; IAEA, 2000. (Laboratory Manual).

MAKKAR, H.P.S.; BLÜMMEL, M.; BECKER, K. Formation of complexes between polyvinyl pyrrolidones or polyethylene glycols and tannins, and their implication in gas production and true digestibility in in vitro techniques. British Journal of Nutrition, v.73, p.897-913, 1995.

MAKKAR, H.P.S.; BLÜMMEL, M.; BOROWY, N.K.; BECKER, K. Gravimetric determination of tannins and their correlations with chemical and protein precipitation methods. Journal of the Science of Food and Agriculture, v.61, p.161-165, 1993.

MAKKAR, H.P.S.; DAWRA, R.K.; SINGH, B. Changes in tannin content, polymerization and protein precipitation capacity in oak (Quercus incana) leaves with maturity. Journal of the Science of Food and Agriculture, v.44, p.301-307, 1988.

MANGAN, J.L. Nutritional effects of tannins in animal feeds. Nutrition Research Reviews, v.1, p.209-231, 1988.

MARTIN, J.S.; MARTIN, M.M.; BERNAYS, E.A. Failure of tannic-acid to inhibit digestion or reduce digestibility of plant protein in gut fluids of insect herbivores - implications for theories of plant defense. Journal of Chemical Ecology, v.13, n.3, p.605-621, 1987. 
MAURICIO, R.M.; MOULD, F.L.; DHANOA, M.S.; OWEN, E.; CHANNA, K.S.; THEODOROU, M.K. Semi automation of the in vitro gas production technique using a pressure transducer. In: ANNUAL MEETING OF THE BRITISH SOCIETY OF ANIMAL SCIENCE, Scarborough, 1998. Posters. Penicuik: BSAS, 1998. p.70.

McDONALD, I. A revised model for the estimation of protein degradability in the rumen. Journal of Agricultural Science, v.96, p251-252, 1981.

McNAUGHTON, S.J. Adaptation of herbivores to season changes in nutrient supply. In: HACKER, J.B.; TERNOUTH, J.H. (Ed.) Nutrition of herbivores. London: Academic Press, 1987. p.391-408.

MUELLER-HARVERY, I. Analysis of hydrolysable tannins. Animal Feed Science and Technology, v.91, p.3-20, 2001.

MUELLER-HARVEY, I.; McALLAN, A.B.; THEODOROU, M.K.; BEEVER, D.E. Phenolics in fibrous crop residues and plants and their effects on digestion and utilization of carbohydrate and proteins in ruminants. In REED, J.D.; CAPPER, B.S.; NEATE, P.J.H. (Ed.) Plant breeding and the nutritive value of crop residues. In: WORKSHOP of ILCA, Addis, Ethiopia, 1987. Proceedings. Addis, Ethiopia, 1987. p.97.

MURDIATU, T.B.; McSWEENEY, C.S.; COWRY, J.B. Hydrolysable tannins in forages: metabolism in sheep. Herbivore Nutrition Research, p.45-46, 1987.

NACZK, M.; NICHOLS, T.; PINK, D.; SOSULSKI, F. condensed tannins in canola hulls. Journal of Agricultural and Food Chemistry, v.42, n.10, p.2196-2200, 1994.

NASCIMENTO FILHO, V.F.; LOBÃO, A.O. Detecção de P-32 em amostras de origem animal e vegetal por efeito Cerenkov, cintilação líquida e detector Geiger-Mueller. Piracicaba: CENA, 1977. 25p. (Boletim Científico, 48). 
NIEZEN, J.H.; WAGHORN, T.S.; WAGHORN, G.C.; CHARLESTON, W.A.G. Internal parasites and lamb production - a role for plants containing condensed tannins? Proc. NZL. Soc. Animal Production, v.53, p.235-238, 1993.

NIKOLIC, J.A.; PAVLICEVIC, A.; ZEBROWSKA, T. Quantitative and qualitative influence of dietary urea on composition of duodenal digesta in calves. Journal of Agricultural Science, v.84, p.469-474, 1975.

OH, H.I.; HOFF, J.E.; ARMSTRONG, G.S.; HAFF, L.A. Hydrophobic interaction in tannin-protein complexes. Journal of Agricultural and Food Chemistry, v.28, p.394-398, 1980.

ØRSKOV, E.R.; McDONALD, I.M. The estimation of protein degradability in the rumen from incubation measurements weighted according to rate of passage. Journal of Agricultural Science, v.92, p.499-503, 1979.

PRINCE, M.L.; BUTLER, L.G. Tannins and nutrition. West Lafayette, Indiana, 1980. 37p. (Indi Report, 272).

RAYUDU, G.V.N.; KADIRVEL, R.; VOHRA, P.V.; KRATZER, F.H. Effect of various agents in alleviating the toxicity of tannic acid for chickens. Poultry Science, v.49, p.1323-1326, 1970.

REED, J.D. Nutritional toxicology of tannins and related polyphenols in forage legumes. Journal of Animal Science, v.75, p.1516-1528, 1995.

SALATINO, A.; MONTEIRO, W.R.; BOMTEMPI, N. Histochemical-localization of phenolic deposits in shoot apices of common species of asteraceae. Annals of Botany, v.61, p.557-559, 1988.

SALES, E.C.J.; EVANGELISTA, A.R.; TEIXEIRA, J.C.; REZENDE, A.V. Proteína bruta e constituintes da parede celular de cultivares de alfafa (Medicago sativa L.) (Compact disc). In: REUNIÃO ANUAL DA SOCIEDADE BRASILEIRA DE ZOOTECNIA, 38., Piracicaba, 2001. Anais. Piracicaba: SBZ, 2001. 
SALUNKHE, D.K.; CHAVAN, J.K.; KADAM, S.S. Dietary tannins: Consequences and remedies. Boca Raton: CRC Press, 1990. p.1-310.

SAS INSTITUTE. The SAS system for windows. Release 8.01. Cary, 2000.

SCALBERT, A. Antimicrobial properties of tannins. Phytochemistry, v.30, p.3875-3883, 1991.

SGARBIERI, V.C. Proteínas em alimentos protéicos: propriedades degradações - modificações. São Paulo: Varela, 1996. cap.5: Deterioração e modificações químicas, fízicas e enzimáticas de proteínas.

SPENCER, C.M.; CAI, Y.; MARTIN, R.; GAFFNEY, S.H.; GOULDING, P.N.; MAGNOLATO, D.; LILLEY, T.H.; HASLAM, E. Polyphenol complexation some thoughts and observations. Phytochemistry, v.27, p.2397-2409, 1988.

SYNGE, R.L.M. Interactions of polyphenols with proteins in plants and plant products. Qualitas Plantarum-Plant Foods for Human Nutrition, v.24, p.337-350, 1975.

TAKECHI, M.; TANAKA, Y.; TAKEHARA, M.; NONAKA, G.; NISHIOKA, I. Structure and antiherpetic activity among the tannins. Phytochemistry, v.24, p.2245-2250, 1985.

TEMMINK, J.H.M.; FIELD, J.A.; VANHAASTRECHT, J.C.; MERKELBACH, R.C.M. Acute and sub-acute toxicity of bark tannins in carp (Cyprinus carpio L) Water Research, v.23, p.341-344, 1989.

TERRILL, T.H.; WAGHORN, G.C.; WOOLLEY, D.J.; McNABB, W.C.; BARRY, T.N. Assay and digestion of ${ }^{14} \mathrm{C}$-labelled condensed tannins in gastrointestinal tract of sheep. British Journal of Nutrition, v.72, p.467477, 1994. 
THEODOROU, M.K.; WILLIAMS, B.A.; DHANOA, M.S.; MCALLAN, A.B.;

FRANCE, J. A simple gas production method using a pressure transducer to determine the fermentation kinetics to ruminant feed. Animal Feed Science and Technology, v.48, p.185-197, 1994.

VAN HOVEN, W. Tannins and digestibility in greater kudu. Canadian Journal of Animal Science, v.64, p.177-178, 1984. Supplement S.

VAN NEVEL, C.J.; DEMEYER, D.I. Determination of rumen microbial growth in vitro from ${ }^{32} \mathrm{P}$ - labeled phosphate incorporation. British Journal of Nutrition, v.38, p.101-114, 1977.

VAN SOEST, P.J.; WINE, R.H. Use of detergent in the analysis of farmers feeds. IV. Determination of plant cell wall constituents. Journal of AOAC, v.50, p.50-55, 1967.

VITTI, D.M.S.S.; SILVA FILHO, J.C. Comparison of energy sources for rumen microorganisms using ${ }^{32} \mathrm{P}$ incorporation. Journal of Nuclear Agriculture and Biology, v.14, p.85-88, 1985.

VITTI, D.M.S.S.; ABDALLA, A.L.; SILVA FILHO, J.C. Influência de componentes fenólicos na atividade dos microrganismos do rúmen. Energia Nuclear na Agricultura, v.7, n.1/2, p.45-52, 1985/86.

WALKER, D.J.; NADER, C.J. Method for measuring microbial growth in rumen content. Applied Microbiology, v.16, n.8, p.1124, 1968.

YOUNG, H.; PETERSON, V.J. Condensed tannins from white clover seed diffusate. Phytochemistry, v.19, p.159-160, 1980.

ZHU, J.; FILLIPICH, L.J.; NG, J. Rumen involvement in sheep tannic acid metabolism. Veterinary and Human Toxicology, v.37, p.436-440, 1995. 